\title{
COMMENTS ON THE APPROXIMATE ELASTIC ANALYSIS OF CONTINUOUS NONPRESTRESSED REINFORCED CONCRETE BEAMS AND PORTAL FRAMES
}

\author{
BAHMAN OMAR TAHA \\ Dept. of Civil Engineering, Erbil Engineering Technical College, Erbil Polytechnic University, \\ Kurdistan Region of -Iraq
}

(Received: July 11, 2018; Accepted for Publication: September 24, 2018)

\begin{abstract}
Approximate analyses methods have been remained important for professional engineers and engineering students, and also it is important in structural analysis specially during preliminary designs. The moment coefficients of two, three, four and five multi-spans continuous nonprestressed reinforced concrete beams are determined and compared with AC I- coefficient method taking different groups of span combinations into consideration. The results show that the ACI- coefficient method of elastic analysis is safe and conservative except at internal support bending moment of $\left(\mathrm{wL}^{2} / 10\right)$ is suggested at both side of the support and $\left(w L^{2} / 12\right)$ ( $w$ is the total factored loads) is suggested at first and last fixed support. Negative moment appears at some midspan and positive moment appears at supports in some span combinations, which is opposite to that obtained by ACI - method. For this reason, designer engineers should take this point into mind in analyzing the continuous beams. Also, the effect of the ratio of beam to column stiffness and height of the column on the end moments and midspan moments of the beams and columns are considered for portal frame.
\end{abstract}

KEYWORDS: Continuous beams, Portal frame, ACI coefficient method.

\section{Notations}

\begin{tabular}{ll} 
Symbol & Meaning \\
\hline fc $^{\prime}$ & cylindrical concrete compressive strength \\
fy & yield strength of the steel bars \\
$\mathrm{h}$ & Column height \\
$\mathrm{Kb}$ & Beam stiffness \\
$\mathrm{Kc}$ & Column stiffness \\
$\mathrm{L}$ & Span length \\
$\mathrm{M}$ & Bending moment \\
$\mathrm{N}$ & Moment coefficient of the beams ends the portal frame \\
$\mathrm{N} 1$ & Moment coefficient of the beams midspan the portal \\
$\mathrm{Pu}$ & frame \\
$\mathrm{RM}$ & Molumn external applied load \\
$\mathrm{W}$ & Total factored load \\
$\alpha$ & moment coefficient \\
$\alpha 1 \& \alpha 2$ & Span length ratio \\
$\phi P n$ & Column internal strength \\
$\psi$ & Ratio of beam stiffness to column stiffness
\end{tabular}




\section{INTRODUCTION}

$\mathbf{T}$ he frame analysis in practice need to simplify by means of certain approximations to determine the moments and shear forces with reasonable accuracy and reducing the amount of computation and possible for hand calculations. The influence of side sway due to vertical loads can be neglected and the moments are determined with sufficient accuracy by dividing the entire frame into simpler subframes. Each of these consists of one continuous beam, plus top and bottom columns, the far ends of the columns are considered fixed [1].

ACI code [2] permits the following loading distribution for floor and roof members:

1. The live load to be applied only on the floor and roof under consideration, and the far ends of the column are fixed.

2. The arrangement of the live load may be limited to combinations:

- Factored dead load on all spans with full factored live load on two adjacent spans, to determine maximum negative moments at supports.

- Factored dead load on all spans with full factored live load on alternative spans, to determine maximum positive moments at mid spans.

Many approximate methods of analysis are used to analyze the indeterminate structures, even with the availability of computers, most engineers find it desirable to make a rough check of results using approximate means, to detect gross errors which is difficult to find when computer software's are used.

Also, in structures of minor importance, it is satisfactory to design on the basis of results obtained by rough calculations, and the values of shear forces and moments determined using approximate methods of analysis.

ACI Code chapter 6 section 6.5 [2] provides approximate calculations of maximum moments and shear forces in continuous beams and one-way slabs. The ACI moment coefficient applicable with the following limitations:

1- There are two or more spans.

2- Members are prismatic.

3- Loads are uniformly distributed.

4- Spans are approximately equal; with $( \pm 20 \%)$ different between two adjacent spans.
5- The ratio of unfactored live load to unfactored dead load not exceed (3).

John and Ranjedran (3); provided a comparative study on exact and approximate methods of structural analysis. The results of analysis by approximate methods compared with the results obtained by using computer software (Staad pro) based on finite element method. They found that the average variation being $20.92 \%$ in the column moment and $10.38 \%$ in the beams.

JingHai $\mathrm{Wu}$ (4); presented the simplified storywise summation method, which was summarized as follows: (I) Divide a building frame into many single-story frames whose number equals the number of stories of the building frames; (2) approximately analyze each single-story frame; and (3) sum the single-story frames. The method is almost as accurate as the existing storywise summation method, and may provide better accuracy than the other approximate methods.

Behr and Henry (5), studied the potential errors in approximate methods of structural analysis. The "revised approximate method" presented in this paper .it was conducted that Inappropriate assumptions in the approximate analysis of vertically loaded rectangular frames can lead to significant errors. Assuming inflection points at both ends of each girder and zero axial force in all girders leads to erroneous results in simple examples. Improved assumptions are required in order to obtain realistic approximate solutions for vertically loaded rectangular frames.

Behr and Henry (6); A reliable, reasonably accurate approximate method of structural analysis for symmetric, rectangular frames under symmetric vertical loadings has been developed. Using the revised assumption sets for either fully loaded or checkerboard-loaded cases, solutions were superior to those from the slightly different set of assumptions found in many contemporary structural analysis textbooks.

Marefat and Farzanian (7); suggested two plastic hinges on both sides of an internal support of a frame instead of on one plastic hinge at the center of joints, continuous frame structure is considered and the effect of lateral load is considered, also redistribution of moments is considered in the analysis of continuous structure using simple solution based on virtual work theory to determine plastic rotation. 
Varia and Patel (8,9 and 10); compared the results of the analysis of continuous beam using relative deformation coefficient method with that obtained by the classical methods (slope deflection and moment distribution methods). They found that the relative deformation coefficient results are close enough to that obtained by the classical methods.

Kolekar and Pawar (11); presented the results of the analysis of continuous beams subjected to uniformly distributed load and earthquake loads. The analysis is done for different plan areas and for different seismic zones. Suitable coefficient is developed in the form of tables based on the results obtained by computer software (Staad pro).

This study presents some differences in the analysis between the ACI coefficient method which is used for the analysis of beams and oneway slab, with the conventional elastic analysis, such as appearing negative moments at the mid span of internal spans of the frame instead of positive moments given by ACI coefficient method. The idea of this paper begins from this point, this study presents a comprehensive study to find all the differences between the ACI coefficient method and elastic analysis, also finding the differences between adjacent span length which cause negative mid span moment. The structural engineers should take these points in the design of buildings.

\section{METHODOLOGY}

This study presents the analysis of continuous beams of multi spans 2, 3, 4 and 5 spans with different combinations of span values, the moment coefficients are obtained and compared with ACIcoefficient method for analysis of beams and oneway slabs.

Also, the effect of the beam to column stiffness ratios and height of the columns are considered on the moment coefficients of portal frame of one and three spans. Different problems are analyzed by using (Staad pro) computer software for this purpose.

The moment coefficients at supports and midspans are determined for different multi spans continuous beams for the following parameters:
1- Two, three, four and five spans.

2- The first span is reference span and equal to (6 $\mathrm{m})$.

3- Span ratio vary between (0.5 and 2.0).

4- Beam dimensions $(400 \mathrm{~mm} \times 600 \mathrm{~mm})$ and column dimensions ( $400 \mathrm{~mm} \times 400 \mathrm{~mm}$ ), common dimensions which are used in many designs and satisfied the deflection control criteria.

5- Uniform distribution load $15.76 \mathrm{kN} / \mathrm{m}$ and $15.00 \mathrm{kN} / \mathrm{m}$. (Total load= Dead load + Live load, Dead load $=$ Self weight + Additional dead load)

6- Two cases of continuous beams are considered.

- The external outer supports are simply supported - The external outer supports are fixed.

7- Three equal spans portal frame with different column heights are analyzed to determine the effect of column heights and the beam to column stiffness ratio on the moment coefficient of the beam and column moments.

8- One span portal frame is analyzed to find effect of the beam to column stiffness ratio on the end and midspan moments.

During the analysis of the continuous beams in some span arrangement combinations negative moment appears at some midspans, and positive moment appears at supports which cannot be obtained while analyzing by the ACI- simplified method of analysis for nonprestressed continuous beams and one-way slabs, which is the important point of that research.

Problem 1: Three span continuous beams, beam size $(400 \mathrm{~mm} \times 600 \mathrm{~mm}), \mathrm{fc}^{`}=28 \mathrm{MPa}, \mathrm{fy}=414$ $\mathrm{MPa}$ and $\mathrm{W}=15.76 \mathrm{kN} / \mathrm{m}$ (figure (1)).

Where: $\mathrm{fc}^{`}=$ cylindrical concrete compressive strength, fy= yield strength of the steel bars

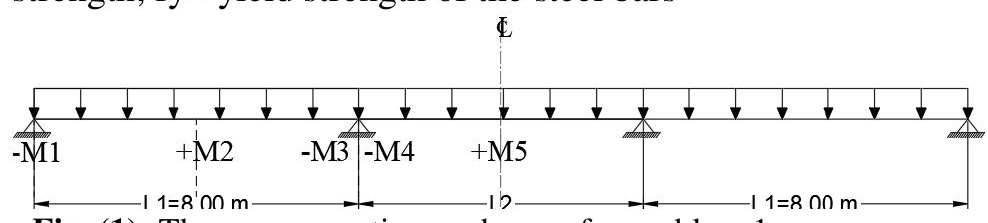

Fig. (1): Three span continuous beams for problem 1

The value of $\mathrm{L} 1$, beam size, fc', fy and $\mathrm{W}$ assumed as a common practical value used in the design projects. 
Table (1): The analysis results (moment coefficient) of problem 1 for different ratio of $\left(\mathrm{L}_{2} / \mathrm{L}_{1}\right)$. $M=\alpha \mathrm{WL}{ }^{2}$

\begin{tabular}{lllllllll}
\hline $\mathrm{L}_{1}$ & $\mathrm{~L}_{2}$ & $\alpha 2=\mathrm{L}_{2} / \mathrm{L}_{1}$ & $\begin{array}{c}\alpha \\
\left(-\mathrm{M}_{1}\right)\end{array}$ & $\begin{array}{c}\alpha \\
\left(+\mathrm{M}_{2}\right)\end{array}$ & $\begin{array}{c}\alpha \\
\left(-\mathrm{M}_{3}\right)\end{array}$ & $\begin{array}{c}\alpha \\
\left(-\mathrm{M}_{4}\right)\end{array}$ & $\begin{array}{c}\alpha \\
\left(+\mathrm{M}_{5}\right)\end{array}$ \\
\hline 8.0 & 6.00 & 0.7500 & 0 & 0.0827 & 0.1083 & 0.1083 & -0.0230 & \\
\hline 8.0 & 6.70 & 0.8375 & 0 & 0.0806 & 0.1033 & 0.1033 & 0.0000 [16.25\% span difference] \\
\hline 8.0 & 7.00 & 0.8750 & 0 & 0.0794 & 0.1018 & 0.1018 & 0.0073 \\
\hline 8.0 & 8.00 & 1.0000 & 0 & 0.0750 & 0.0990 & 0.0990 & 0.0250 \\
\hline ACl-Coff. Method & 1.0000 & 0 & 0.0910 & 0.1000 & 0.0910 & 0.0630 & \\
\hline
\end{tabular}

As shown in table 1 the (+ve) moment of the $1^{\text {st }}$ span decreased with increasing span ratio $(\alpha 2=$ $\mathrm{L}_{2} / \mathrm{L}_{1}$ ), also the (-ve) moment at internal support is decreased when the span ratio less than $(83.75 \%)$, negative moment appears at mid span of the $2^{\text {nd }}$ internal span which is not appear in ACIcoefficient method $\alpha 2=0.8375$, midspan moment of $2^{\text {nd }}$ span is zero, over this value (+ve) moment appear in the $2^{\text {nd }}$ span. The difference between adjacent spans which is permitted in ACI-method is $(\% 20)$ while in this example $(\% 16.25)$. For this reason, finite element method or moment distribution method is adopted when the difference between adjacent span reach to this value.

For span ratio value $(\alpha 2=1.0)$, that is equal spans, the results of moment coefficient given by ACI-method is more than obtained by finite element method, this mean that the ACI-method results are safe and conservative, except at the internal support, it is suggested to use moment coefficient (0.10) at both sides of the support.

The same results and conclusions are obtained when the spans value is changed, as show in problem 2.

Problem 2: Three span continuous beams, beam size $(400 \mathrm{~mm} \times 600 \mathrm{~mm}), \mathrm{fc}^{`}=28 \mathrm{MPa}, \mathrm{fy}=414$ $\mathrm{MPa}$ and $\mathrm{W}=15.76 \mathrm{kN} / \mathrm{m}$ (figure (2)).

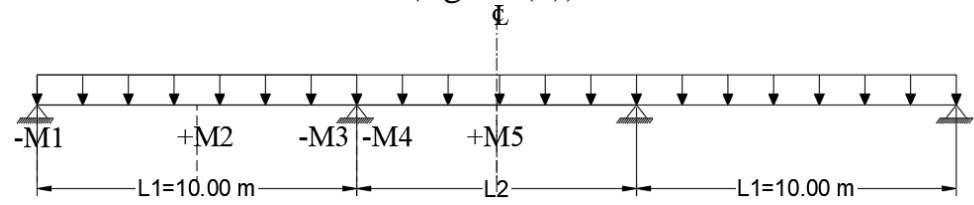

Fig. (2): Three span continuous beams for problem 2

Table (2): The analysis results (moment coefficient) of problem 2 for different ratio of $\left(\mathrm{L}_{2} / \mathrm{L}_{1}\right)$. $M=\alpha W L^{2}$

\begin{tabular}{cccccccc}
\hline $\mathrm{L}_{1}$ & $\mathrm{~L}_{2}$ & $\alpha 2=\mathrm{L}_{2} / \mathrm{L}_{1}$ & $\begin{array}{c}\alpha \\
\left(-\mathrm{M}_{1}\right)\end{array}$ & $\begin{array}{c}\alpha \\
\left(+\mathrm{M}_{2}\right)\end{array}$ & $\begin{array}{c}\alpha \\
\left(-\mathrm{M}_{3}\right)\end{array}$ & $\begin{array}{c}\alpha \\
\left(-\mathrm{M}_{4}\right)\end{array}$ & $\begin{array}{c}\alpha \\
\left.+\mathrm{M}_{5}\right)\end{array}$ \\
\hline 10.0 & 5.00 & 0.500 & 0 & 0.0849 & 0.1427 & 0.1427 & -0.1960 \\
\hline 10.0 & 6.00 & 0.600 & 0 & 0.0850 & 0.1249 & 0.1249 & -0.0970 \\
\hline 10.0 & 7.00 & 0.700 & 0 & 0.0841 & 0.1132 & 0.1132 & -0.0420 \\
\hline 10.0 & 8.00 & 0.800 & 0 & 0.0822 & 0.1060 & 0.1060 & -0.0091 \\
\hline 10.0 & 8.35 & 0.835 & 0 & 0.0814 & 0.1035 & 0.1035 & $0.0000[16.5 \%$ span difference] \\
\hline 10.0 & 9.00 & 0.900 & 0 & 0.0790 & 0.1018 & 0.1018 & 0.0116 \\
\hline 10.0 & 10.00 & 1.000 & 0 & 0.0750 & 0.0990 & 0.0990 & 0.0250 \\
\hline \multicolumn{2}{l}{ ACl-Coff. Method } & 1.0000 & 0 & 0.0910 & 0.1000 & 0.0910 & 0.0630 \\
\hline
\end{tabular}

Problem 3: Three span continuous beams, with external support is fixed beam size (400 $\mathrm{mm} \times 600 \mathrm{~mm})$, $\mathrm{fc}^{`}=28 \mathrm{MPa}$, fy=414 $\mathrm{MPa}$ and $\mathrm{W}=15.76 \mathrm{kN} / \mathrm{m}$ (figure (3)).

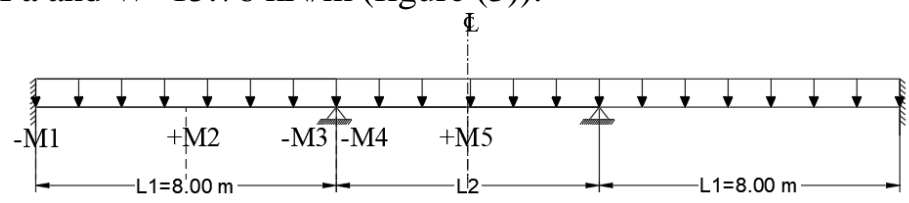

Fig. (3): Three span continuous beams for problem 3 
Table (3): The analysis results (moment coefficient) of problem 3 for different ratio of $\left(\mathrm{L}_{2} / \mathrm{L}_{1}\right)$. $M=\alpha \mathrm{WL} \mathrm{L}^{2}$

\begin{tabular}{cccccccc}
\hline$L_{1}$ & $\mathrm{~L}_{2}$ & $\alpha 2=\mathrm{L}_{2} / \mathrm{L}_{1}$ & $\begin{array}{c}\alpha \\
\left(-\mathrm{M}_{1}\right)\end{array}$ & $\begin{array}{c}\alpha \\
\left(+\mathrm{M}_{2}\right)\end{array}$ & $\begin{array}{c}\alpha \\
\left(-\mathrm{M}_{3}\right)\end{array}$ & $\begin{array}{c}\alpha \\
\left(-\mathrm{M}_{4}\right)\end{array}$ & $\begin{array}{c}\alpha \\
\left(+\mathrm{M}_{5}\right)\end{array}$ \\
\hline 8.0 & 4.00 & 0.5000 & 0.0988 & 0.0495 & 0.0890 & 0.0890 & -0.0840 \\
\hline 8.0 & 5.00 & 0.6250 & 0.0970 & 0.0488 & 0.0837 & 0.0837 & -0.0165 \\
\hline 8.0 & 5.40 & 0.6750 & 0.0962 & 0.0482 & 0.0818 & 0.0818 & -0.0010 \\
\hline 8.0 & 5.45 & 0.6813 & 0.0960 & 0.0480 & 0.0816 & 0.0816 & 0.0000 [32\% span difference] \\
\hline 8.0 & 6.00 & 0.7500 & 0.0941 & 0.0472 & 0.0804 & 0.0804 & 0.0156 \\
\hline 8.0 & 7.00 & 0.8750 & 0.0895 & 0.0448 & 0.0807 & 0.0807 & 0.0323 \\
\hline 8.0 & 8.00 & 1.0000 & 0.0833 & 0.0417 & 0.0833 & 0.0833 & 0.0417 \\
\hline ACl-Coff. Method & 1.0000 & 0.0630 & 0.0714 & 0.1000 & 0.0910 & 0.0630 \\
\hline
\end{tabular}

The (-ve) moment at $1^{\text {st }}$ support decreased with increasing the span ratio $\left(\alpha 2=\mathrm{L}_{2} / \mathrm{L}_{1}\right)$, also the (+ve) $1^{\text {st }}$ midspan moment is decreased, while the (-ve) moment at internal support decreased with increasing $(\alpha 2)$ until the value $(\alpha 2=0.75)$, then begin increasing up to $(\alpha 2=1.0)$, at span ratio $(\alpha 2=0.6813)$, that is different between two adjacent spans about (\%32), zero moment is obtained, below this ratio (-ve) moment is appear at midspan, which is opposite to that obtained by ACI-coefficient method. figure (4) shows the variation of the moment coefficient with respect to span ratio $(\alpha 2)$. The result of $(\alpha 2=1.0)$, that is equal spans, of ACI-method are adequate for all locations, except at $1^{\text {st }}$ support, the (-ve) moment should be $\left(\mathrm{WL}^{2} / 12\right)$ instead of $\left(\mathrm{WL}^{2} / 16\right)$.

The relationship of the moment coefficients with span ratio $(\alpha 2)$ are shown in figure (4). The same conclusions are obtained when the span $\left(\mathrm{L}_{1}\right)$ is changed as shown in problem 4.

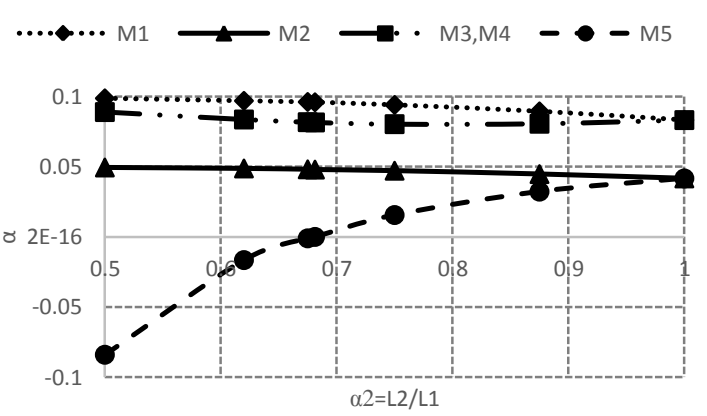

Fig. (4): Moment Coff. of Problem 3 Versus Span Ratio $(\alpha 2)$

Problem 4: Three span continuous beams, with external support is fixed beam size (400 $\mathrm{mm} \times 600$ $\mathrm{mm}), \mathrm{fc}^{\prime}=28 \mathrm{MPa}, \mathrm{fy}=414 \mathrm{MPa}$ and $\mathrm{W}=15.76$ $\mathrm{kN} / \mathrm{m}$ figure (5).

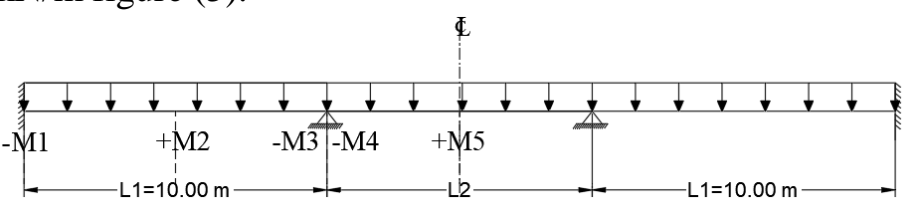

Fig. (5): Three span continuous beams for problem 4

Table (4): The analysis results (moment coefficient) of problem 4 for different ratio of $\left(\mathrm{L}_{2} / \mathrm{L}_{1}\right)$. $M=\alpha \mathrm{WL} \mathrm{L}^{2}$

\begin{tabular}{lllccccll}
\hline $\mathrm{L}_{1}$ & $\mathrm{~L}_{2}$ & $\alpha 2=\mathrm{L}_{2} / \mathrm{L}_{1}$ & $\begin{array}{c}\alpha \\
\left(-\mathrm{M}_{1}\right)\end{array}$ & $\begin{array}{c}\alpha \\
\left(+\mathrm{M}_{2}\right)\end{array}$ & $\begin{array}{c}\alpha \\
\left(-\mathrm{M}_{3}\right)\end{array}$ & $\begin{array}{c}\alpha \\
\left(-\mathrm{M}_{4}\right)\end{array}$ & $\begin{array}{c}\alpha \\
\left(+\mathrm{M}_{5}\right)\end{array}$ \\
\hline 8.0 & 5.00 & 0.5000 & 0.0988 & 0.0495 & 0.0928 & 0.0928 & -0.0840 & \\
\hline 8.0 & 6.00 & 0.6000 & 0.0977 & 0.0490 & 0.0849 & 0.0849 & -0.0260 & \\
\hline 8.0 & 6.80 & 0.6800 & 0.0960 & 0.0480 & 0.0816 & 0.0816 & 0.0000 [32\% span difference] \\
\hline 8.0 & 7.00 & 0.7000 & 0.0956 & 0.0479 & 0.0811 & 0.0811 & 0.0054 \\
\hline 8.0 & 8.00 & 0.8000 & 0.0925 & 0.0463 & 0.0802 & 0.0802 & 0.0236 \\
\hline 8.0 & 10.00 & 1.0000 & 0.0833 & 0.0417 & 0.0833 & 0.0833 & 0.0417 & \\
\hline ACl-Coff. Method & 1.0000 & 0.0630 & 0.0714 & 0.1000 & 0.0910 & 0.0630 & \\
\hline
\end{tabular}


Problem 5: Four equal continuous beams, with external support is simply supported beam size (400 mm x $600 \mathrm{~mm})$, $\mathrm{fc}^{`}=28 \mathrm{MPa}$, fy=414 MPa and $\mathrm{W}=15.76 \mathrm{kN} / \mathrm{m}^{2}$ (figure (6)).

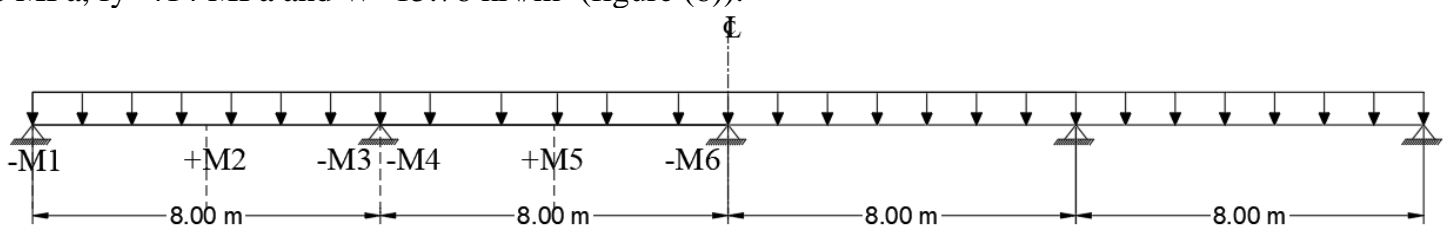

Fig. (6): Four equal continuous beams for problem 5

Table (5): The analysis results (moment coefficient) of problem 5. $\mathrm{M}=\alpha \mathrm{WL}^{2}$

\begin{tabular}{ccccccc}
\hline & $\begin{array}{c}\alpha \\
\left(-\mathrm{M}_{1}\right)\end{array}$ & $\begin{array}{c}\alpha \\
\left(+\mathrm{M}_{2}\right)\end{array}$ & $\begin{array}{c}\alpha \\
\left(-\mathrm{M}_{3}\right)\end{array}$ & $\begin{array}{c}\alpha \\
\left(-\mathrm{M}_{4}\right)\end{array}$ & $\begin{array}{c}\alpha \\
\left(+\mathrm{M}_{5}\right)\end{array}$ & $\begin{array}{c}\alpha \\
(-\mathrm{M} 6)\end{array}$ \\
\hline FEM & 0 & 0.072 & 0.106 & 0.106 & 0.036 & 0.071 \\
\hline ACl-Coff. Method & 0 & 0.091 & 0.100 & 0.091 & 0.063 & 0.091 \\
\hline
\end{tabular}

The results of ACI-method are safe and conservative, except at interior support, the result of $\left(\mathrm{wL}^{2} / 9\right)$ is suggested at both sides of the support.

Problem 6: Three equal span portal frame figure $(7 \& 8)$ is analyzed to find the effect of column height and beam to column stiffness ratio on the moment coefficients of beams \& columns. Column size (400 mm x $400 \mathrm{~mm}$ ), beam size (400 $\mathrm{mm} \times 600 \mathrm{~mm}), \mathrm{fc}^{`}=28 \mathrm{MPa}, \mathrm{fy}=414 \mathrm{MPa}$ and $\mathrm{W}=15.76 \mathrm{kN} / \mathrm{m}$. The result of the analysis is shown below.

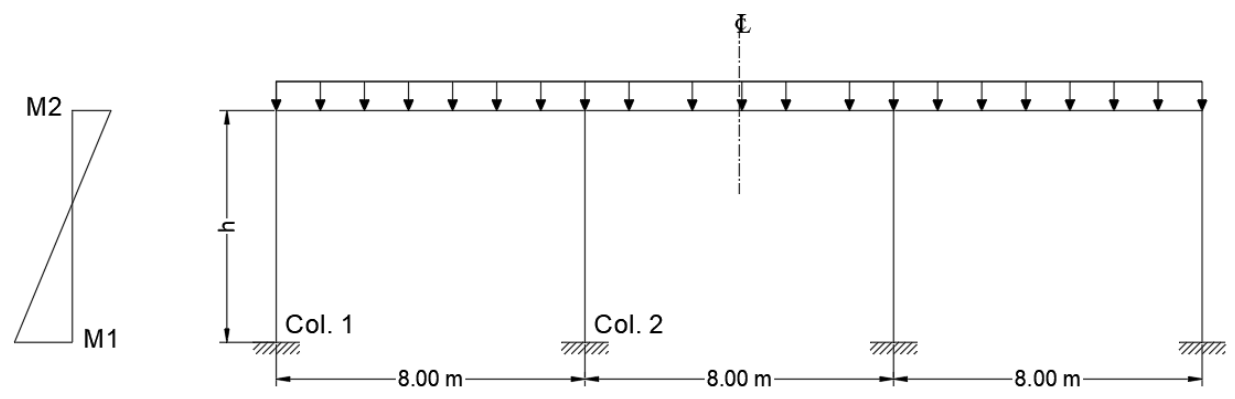

Fig. (7): Three equal span portal frame for problem 6

Table (6): The analysis results (moment coefficient) of problem 6 for columns. $M=\alpha \mathrm{WL}^{2}$

\begin{tabular}{|c|c|c|c|c|c|c|c|c|c|c|c|c|}
\hline \multirow[b]{2}{*}{$\begin{array}{l}\widehat{\Xi} \\
\check{\Xi} \\
\dot{\infty}\end{array}$} & \multirow[b]{2}{*}{$\begin{array}{l}\frac{0}{y} \\
\frac{y}{y} \\
\dot{+}\end{array}$} & \multirow{2}{*}{ 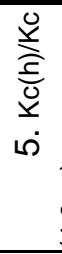 } & \multirow[b]{2}{*}{$\begin{array}{l}\dot{y} \\
\underline{a} \\
\end{array}$} & \multirow{2}{*}{ 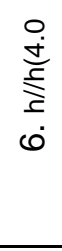 } & \multicolumn{4}{|c|}{ Col 1} & \multicolumn{4}{|c|}{ Col 2} \\
\hline & & & & & $\stackrel{N}{\Sigma}$ & 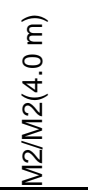 & $\Sigma$ & 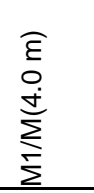 & $\stackrel{N}{\Sigma}$ & $\begin{array}{l}\widehat{E} \\
o \\
\text { d } \\
\text { N } \\
\text { N }\end{array}$ & $\Sigma$ & 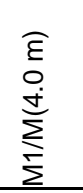 \\
\hline 4.0 & 0.60 & 1.0 & 1.67 & 1.0 & 0.0340 & 1.000 & -0.0160 & 1.000 & -0.0077 & 1.000 & 0.00322 & 1.000 \\
\hline 6.0 & 0.40 & 0.67 & 2.50 & 1.5 & 0.0260 & 0.768 & -0.0130 & 0.808 & -0.0065 & 0.842 & 0.00321 & 0.997 \\
\hline 8.0 & 0.30 & 0.50 & 3.33 & 2.0 & 0.0216 & 0.633 & -0.0108 & 0.673 & -0.0055 & 0.720 & 0.00275 & 0.852 \\
\hline 10.0 & 0.24 & 0.40 & 4.20 & 2.5 & 0.0185 & 0.542 & -0.0092 & 0.575 & -0.0048 & 0.625 & 0.00239 & 0.742 \\
\hline
\end{tabular}

Where:

$\mathrm{Kc}=$ Column stiffness

$\mathrm{Kb}=$ Beam stiffness

$\mathrm{h}=$ Column height 


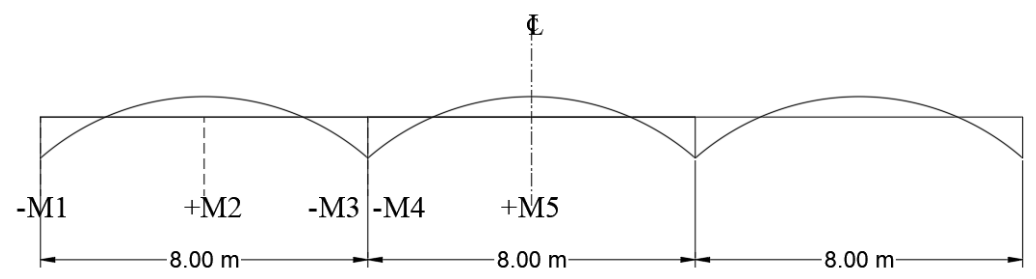

Fig. (8): Three equal span portal frame for problem 6

Table (7): The analysis results (moment coefficient) of problem 6 for Beams. $M=\alpha \mathrm{WL}^{2}$

\begin{tabular}{|c|c|c|c|c|c|c|c|c|c|c|}
\hline & & & & & \multicolumn{5}{|c|}{ Ratio of $\mathrm{M} / \mathrm{M}(4.0 \mathrm{~m})$} \\
\hline $\mathrm{h}(\mathrm{m})$ & $\begin{array}{c}\alpha \\
\left(-\mathrm{M}_{1}\right)\end{array}$ & $\begin{array}{c}\alpha \\
\left(+\mathrm{M}_{2}\right)\end{array}$ & $\begin{array}{c}\alpha \\
\left(-\mathrm{M}_{3}\right)\end{array}$ & $\begin{array}{c}\alpha \\
\left(-\mathrm{M}_{4}\right)\end{array}$ & $\begin{array}{c}\alpha \\
\left(+\mathrm{M}_{5}\right)\end{array}$ & $\mathrm{RM}_{1}$ & $\mathrm{RM}_{2}$ & $\mathrm{RM}_{3}$ & $\mathrm{RM}_{4}$ & $\mathrm{RM}_{5}$ \\
\hline 4.0 & 0.0340 & 0.0590 & 0.0970 & 0.0890 & 0.0357 & 1.000 & 1.000 & 1.000 & 1.000 & 1.000 \\
\hline 6.0 & 0.0260 & 0.0630 & 0.0974 & 0.0910 & 0.0340 & 0.768 & 1.060 & 1.005 & 1.020 & 0.952 \\
\hline 8.0 & 0.0216 & 0.0650 & 0.0976 & 0.0920 & 0.0329 & 0.633 & 1.100 & 1.007 & 1.032 & 0.920 \\
\hline 1.0 & 0.0185 & 0.0670 & 0.0977 & 0.0929 & 0.032 & 0.542 & 1.125 & 1.008 & 1.040 & 0.900 \\
\hline
\end{tabular}

The results shown that end moment of the column decreased with increasing the column height, because the stiffness of the column reduced with increasing the column height, then less moments are developed at the ends. The end moments of the first support of the beam decreased with increasing the column height, while at internal support the (-ve) moment is increased. The midspan (+ve) moment of $1^{\text {st }}$ span increased while in second span is decreased with increasing the column height.

This mean that it is better to provide suitable columns height to minimize the end moments, that is minimizing the eccentricity of the load which has greater effect on the internal capacity of the columns, with the condition that the column internal strength $(\phi \mathrm{Pn})$ should be greater than the external load $(\mathrm{Pu})$.
The same conclusions are obtained when different loads are applied on alternate spans as shown in (problem 7), except that (-ve) moment is appear at the midspan of the middle span instead of (+ve) moment, this behavior is important and should be taken into consideration when the frames are analyzed and designed.

Problem 7: Three equal span portal frame is analyzed to find the effect of column height, beam to column stiffness ratio and different loading on the moment coefficients of beams \& columns. Column size (400 mm x $400 \mathrm{~mm}$ ), beam size (400 $\mathrm{mm} \times 600 \mathrm{~mm}), \mathrm{fc}^{\prime}=28 \mathrm{MPa}$ and $\mathrm{fy}=414 \mathrm{MPa}$ the result of the analysis is shown below figures $(9 \&$ $10)$.

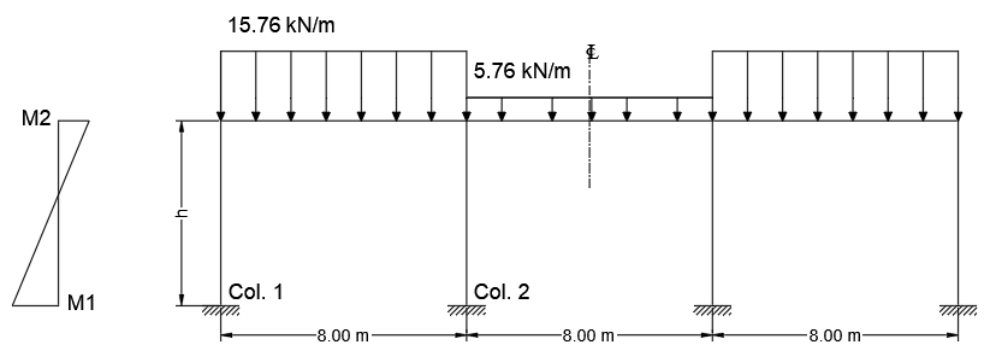

Fig. (9): Three equal span portal frame for problem 7 
Table (8): The analysis results (moment coefficient) of problem 7 for columns. $\mathrm{M}=\alpha \mathrm{WL}^{2}$

\begin{tabular}{|c|c|c|c|c|c|c|c|c|}
\hline & \multirow[b]{2}{*}{$\frac{\hat{Y}}{\underline{y}}$} & \multirow[b]{2}{*}{ 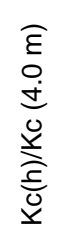 } & \multirow[b]{2}{*}{$\begin{array}{l}\stackrel{0}{Y} \\
\frac{2}{2}\end{array}$} & \multirow[b]{2}{*}{$\begin{array}{l}\widehat{E} \\
0 \\
\dot{J} \\
\end{array}$} & \multicolumn{2}{|c|}{ Col 1} & \multicolumn{2}{|c|}{$\mathrm{Col} 2$} \\
\hline & & & & & $\stackrel{N}{\Sigma}$ & 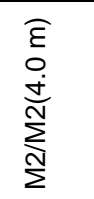 & $\stackrel{N}{\Sigma}$ & 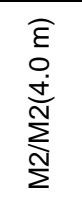 \\
\hline 4.0 & 0.60 & 1.0 & 1.67 & 1.0 & 0.0380 & 1.000 & 0.0238 & 1.000 \\
\hline 6.0 & 0.40 & 0.67 & 2.50 & 1.5 & 0.0300 & 0.800 & 0.0187 & 0.788 \\
\hline 8.0 & 0.30 & 0.50 & 3.33 & 2.0 & 0.0250 & 0.662 & 0.0155 & 0.649 \\
\hline 10.0 & 0.24 & 0.40 & 4.20 & 2.5 & 0.0215 & 0.566 & 0.0130 & 0.552 \\
\hline
\end{tabular}

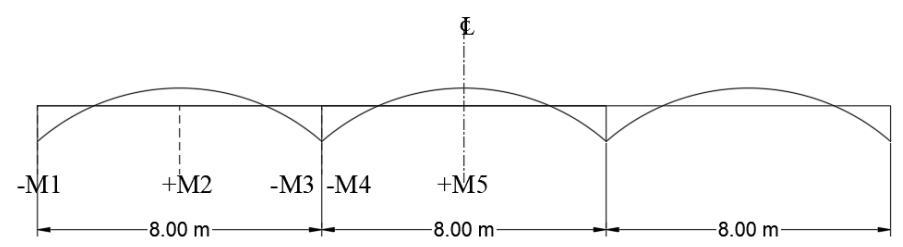

Fig. (10): Three equal span portal frame for problem 7

Table (9): The analysis results (moment coefficient) of problem 7 for Beams. $\mathrm{M}=\alpha \mathrm{WL}^{2}[\mathrm{~W}=15.76 \mathrm{kN} / \mathrm{m}$ on all the spans]

\begin{tabular}{lllllllllll}
\hline & & & & & \multicolumn{5}{c}{ Ratio of $\mathrm{M} / \mathrm{M}(4.0 \mathrm{~m})$} \\
\hline $\mathrm{h}(\mathrm{m})$ & $-\mathrm{M}_{1}$ & $+\mathrm{M}_{2}$ & $-\mathrm{M}_{3}$ & $-\mathrm{M}_{4}$ & $+\mathrm{M}_{5}$ & $\mathrm{RM}_{1}$ & $\mathrm{RM}_{2}$ & $\mathrm{RM}_{3}$ & $\mathrm{RM}_{4}$ & $\mathrm{RM}_{5}$ \\
\hline 4.0 & 0.0380 & 0.0680 & 0.0740 & 0.0503 & -0.0055 & 1.000 & 1.000 & 1.000 & 1.000 & 1.000 \\
\hline 6.0 & 0.0300 & 0.0730 & 0.0726 & 0.0538 & -0.0090 & 0.800 & 1.078 & 0.980 & 1.070 & 1.635 \\
\hline 8.0 & 0.0250 & 0.0760 & 0.0716 & 0.0561 & -0.0112 & 0.662 & 1.113 & 0.965 & 1.114 & 2.050 \\
\hline 1.0 & 0.0215 & 0.0780 & 0.0708 & 0.0577 & -0.0128 & 0.566 & 1.145 & 0.955 & 1.146 & 2.340 \\
\hline
\end{tabular}

The M4 \& M5 determined with respect to Wtotal $=15.76 \mathrm{kN} / \mathrm{m}$ for the table above, if the load $\mathrm{W}=5.76 \mathrm{kN} / \mathrm{m}$, the coeff. of M4 \& M5 become:

Table (10): The analysis results (moment coefficient) of problem 7 for Beams. $\mathrm{M}=\alpha \mathrm{WL}^{2}$ [Wtotal $=5.76 \mathrm{kN} / \mathrm{m}$ ]

\begin{tabular}{lll}
\hline $\mathrm{h}(\mathrm{m})$ & $-\mathrm{M}_{4}$ & $+\mathrm{M}_{5}$ \\
\hline 4.0 & 0.1377 & -0.0150 \\
\hline 6.0 & 0.1473 & -0.0245 \\
\hline 8.0 & 0.1535 & -0.0308 \\
\hline 1.0 & 0.1579 & -0.0351 \\
\hline
\end{tabular}

Problem 8: Single span portal frame with different spans (L) and height (h) values figure (11) are analyzed to find the effect of the stiffness ratio ( $\psi=$ Beam stiffness/Column stiffness) on the end moments and mid span moment of the beam and column. $\mathrm{fc}^{\prime}=28 \mathrm{MPa}, \mathrm{fy}=414 \mathrm{MPa}$.

The results of the analysis are shown in the table (11)

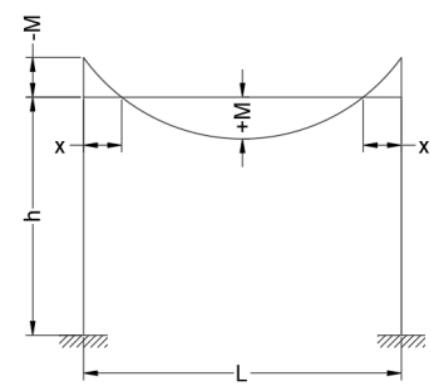

Fig. (11): Single span portal frame 8

$\psi=\mathrm{K}$ beam $/ \mathrm{K}$ column, $\mathrm{M}_{\text {end }}=\mathrm{WL}^{2} / \mathrm{N}$ and $\mathrm{M}_{\text {mid }}=\mathrm{WL}^{2} / \mathrm{N} 1$ $\mathbf{N}=$ moment coefficient of the beams ends the portal frame

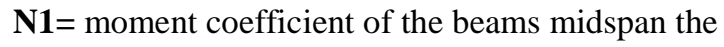
portal frame

Table (11): The analysis results (moment coefficient) of problem 8

\begin{tabular}{ccclc}
\hline$\Psi$ & $\mathrm{N}$ & $\mathrm{N} 1$ & Mend/Mmid & $\mathrm{x} / \mathrm{L}$ \\
\hline 0.00 & 12.000 & 24.000 & 2.000 & 0.2113 \\
\hline 0.05 & 12.342 & 22.707 & 1.8400 & 0.2033 \\
\hline 0.10 & 12.654 & 21.723 & 1.7168 & 0.1967 \\
\hline 0.15 & 12.964 & 20.860 & 1.6093 & 0.1905 \\
\hline
\end{tabular}




\begin{tabular}{lllll}
\hline 0.20 & 13.275 & 20.106 & 1.5145 & 0.1847 \\
\hline 0.30 & 13.900 & 18.830 & 1.3550 & 0.1740 \\
\hline 0.50 & 15.140 & 16.945 & 1.1190 & 0.1567 \\
\hline 1.00 & 18.250 & 14.250 & 0.7800 & 0.1267 \\
\hline 2.00 & 24.100 & 11.964 & 0.4963 & 0.0900 \\
\hline 5.00 & 42.020 & 9.874 & 0.2350 & 0.0500 \\
\hline 10.00 & 72.000 & 8.995 & 0.1250 & 0.0300 \\
\hline$\infty$ & 0.000 & 8.000 & 0.000 & 0.0000 \\
\hline
\end{tabular}

Figure (12) shows that with increasing the ratio of the beams stiffness to the column stiffness the midspan moment increased while the beams moment decreased.

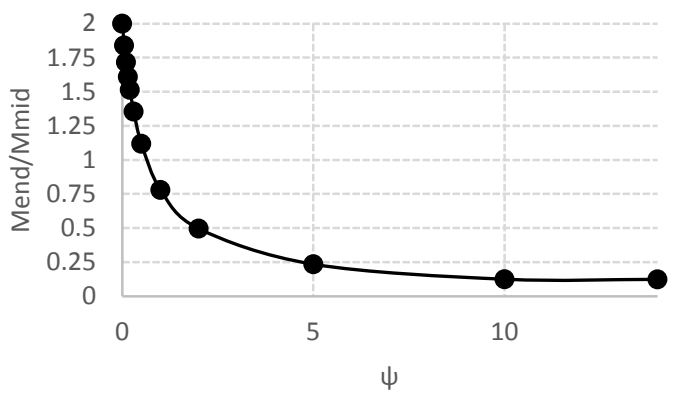

Fig. (12): Effect of stiffness ratio on the ratio of end moment to mid span moment of the beam.

Figure (13) shows that with increasing the ratio of the beams stiffness to the column stiffness the ratio of zero moment distance to the beams length decreased.

In this part of the study, the effect of the multi span (2,3,4 and 5) and external support condition (simple or fixed) are considered in the following problems (figures $(14,15,16 \& 17))$.

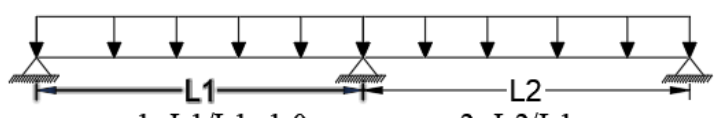

$\alpha 1=\mathrm{L} 1 / \mathrm{L} 1=1.0$ $\alpha 2=\mathrm{L} 2 / \mathrm{L} 1$

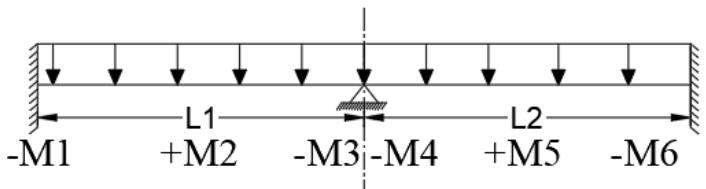

Fig. (14): Two span beams with simply supported and fixed supports.

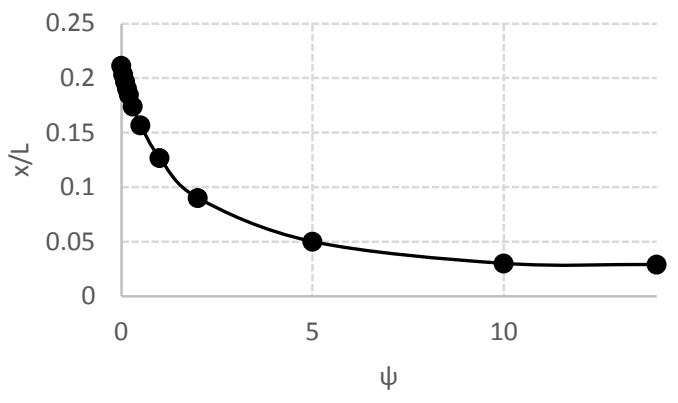

Fig. (13): Effect of stiffness ratio on the inflection distance ratio $(\mathrm{x} / \mathrm{L}$

- Two spans: $\mathrm{fc} \mathrm{c}^{\prime}=28 \mathrm{MPa}, \mathrm{fy}=414 \mathrm{MPa}, \mathrm{Beam}$ size $400 \mathrm{~mm} \times 600 \mathrm{~mm}$ and $\mathrm{W}=15 \mathrm{kN} / \mathrm{m}$ (figure 14)

- Three spans: $\mathrm{fc}^{`}=28 \mathrm{MPa}, \mathrm{fy}=414 \mathrm{MPa}$, Beam size $400 \mathrm{~mm} \times 600 \mathrm{~mm}$ and $\mathrm{W}=15 \mathrm{kN} / \mathrm{m}$ (figure 15)

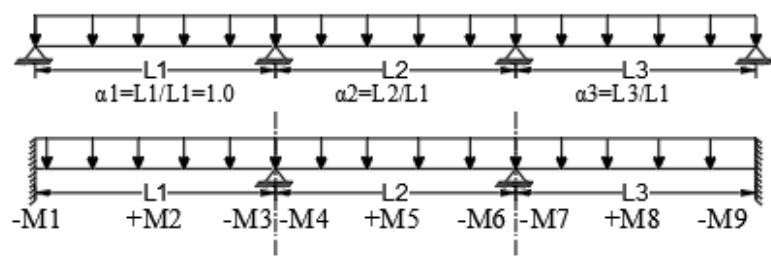

Fig. (15): Three span beams with simply supported and fixed supports

- Four spans: $\mathrm{fc}^{`}=28 \mathrm{MPa}, \mathrm{fy}=414 \mathrm{MPa}$, Beam size $400 \mathrm{~mm}$ x $600 \mathrm{~mm}$ and $\mathrm{W}=15 \mathrm{kN} / \mathrm{m}$ (figure 16)

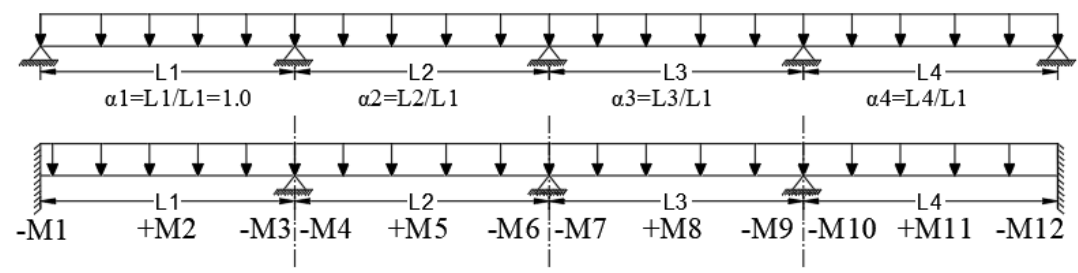

Fig. (16): Four span beams with simply supported and fixed supports. 
-Five Five spans: $\mathrm{fc}^{`}=28 \mathrm{MPa}, \mathrm{fy}=414 \mathrm{MPa}$, Beam size $400 \mathrm{~mm}$ x $600 \mathrm{~mm}$ and $\mathrm{W}=15 \mathrm{kN} / \mathrm{m}$ (figure 17)

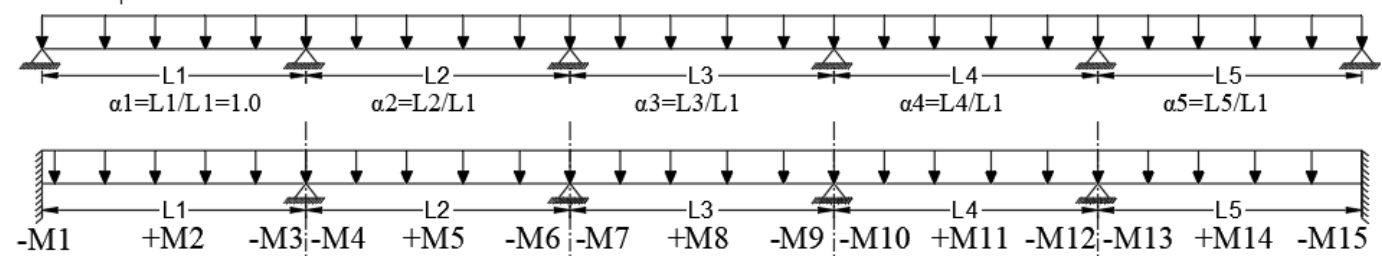

Fig. (17): Five span beams with simply supported and fixed supports.

The results of the analysis of all problems (2, 3, 4 and 5) continuous beams are shown in tables (12 to 19$)$.

Figures A1\&A2 (appendix A) show the effect of span ratio $(\alpha 2)$ on the moment coefficient of two spans continuous beams when the external support is simply supported and fixed respectively. For both cases the +ve moment at first mid span decreased with increasing span ratio $(\alpha 2)$ and become (-ve) beyond ( $\alpha 2=1.5$, and 1.75) for both cases respectively. The (-ve) moment at internal support decreased with increasing $(\alpha 2)$ up to value $(\alpha 2=1.0)$ and then begin to increased up to value $(\alpha 2=2.0)$. The moment coefficient at $2^{\text {nd }}$ mid span is negative at $(\alpha 2=0.5)$ then increased with increasing span ratio, this mean, when the $2^{\text {nd }} \operatorname{span}$ length less than the $1^{\text {st }}$ span length by more than $(50 \%)$, negative moment appear at mid span of the $2^{\text {nd }}$ span instead positive moment, this behavior should be taken into consideration by the designer engineers.

The (-ve) moment of the $1^{\text {st }}$ fixed support decreased with increasing span ratio $(\alpha 2)$ while the last fixed support is increased rapidly up to ratio $(\alpha 2=1.0)$, then gradually increased up to $(\alpha 2=1.0)$.

The same behavior and conclusions are obtained in three spans continuous beams as shown in figures (A3, A4 \& A5) and figures (A6, A7 \& A8), for both cases the outer external supports are simply supported and fixed respectively.

In 4 spans \& 5 spans continues beams, different groups of span combinations are considered, (-ve) moments are appear at mid spans in some groups instead of (+ve) moments as indicated in ACIcoefficient for this reason, FEM or moment distribution method is adopted instead of ACIcoeff. method, and the designer engineers should take this behavior into consideration in analyzing the continues beams, as shown in table (16 to 19), and figures (A9 to A32).

Table (12): Results of (moment coefficient) for continues two spans for different values of $(\alpha 2)$, the external supports are simply supported.

\begin{tabular}{|c|c|c|c|c|c|c|c|c|c|}
\hline & & & $\frac{8}{-\mathrm{M} 1}$ & $\begin{array}{l}\vec{v} \\
+\mathrm{L} 1 \frac{}{\mathrm{M} 2}\end{array}$ & $\stackrel{\nabla}{=} \underset{-\mathrm{M} 3-\mathrm{M} 4}{=}$ & $\begin{array}{l}\vec{v} \\
+\mathrm{L} 2- \\
+\mathrm{M} 5\end{array}$ & $\frac{\vec{x}}{-\mathrm{M} 6}$ & & \\
\hline$\alpha 1$ & $\alpha 2$ & $\mathrm{~L}_{1}(\mathrm{~m})$ & $\mathrm{L}_{2}(\mathrm{~m})$ & $\begin{array}{c}\alpha \\
\left(-M_{1}\right)\end{array}$ & $\begin{array}{c}\alpha \\
\left(+M_{2}\right) \\
\end{array}$ & $\begin{array}{c}\alpha \\
\left(-M_{3}\right)\end{array}$ & $\begin{array}{c}\alpha \\
\left(-M_{4}\right)\end{array}$ & $\begin{array}{c}\alpha \\
\left(+M_{5}\right) \\
\end{array}$ & $\begin{array}{c}\alpha \\
\left(-M_{6}\right) \\
\end{array}$ \\
\hline 1.0 & 0.50 & 6.0 & 3.0 & 0 & 0.0788 & \multicolumn{2}{|c|}{0.0164} & $(-0.0600)$ & 0 \\
\hline 1.0 & 0.75 & 6.0 & 4.5 & 0 & 0.0747 & \multicolumn{2}{|c|}{0.1315} & 0.0355 & 0 \\
\hline 1.0 & 1.00 & 6.0 & 6.0 & 0 & 0.0630 & \multicolumn{2}{|c|}{0.1242} & 0.0629 & 0 \\
\hline 1.0 & 1.25 & 6.0 & 7.5 & 0 & 0.0434 & \multicolumn{2}{|c|}{0.1290} & 0.0728 & 0 \\
\hline 1.0 & 1.50 & 6.0 & 9.0 & 0 & 0.0161 & \multicolumn{2}{|c|}{0.1394} & 0.0766 & 0 \\
\hline 1.0 & 1.75 & 6.0 & 10.5 & 0 & $(-0.0190)$ & \multicolumn{2}{|c|}{0.1523} & 0.0780 & 0 \\
\hline 1.0 & 2.0 & 6.0 & 12.0 & 0 & $(-0.0619)$ & \multicolumn{2}{|c|}{0.1661} & 0.0783 & 0 \\
\hline
\end{tabular}


Table (13): Results of (moment coefficient) for continues two spans for different values of ( $\alpha 2)$, the external supports are fixed.

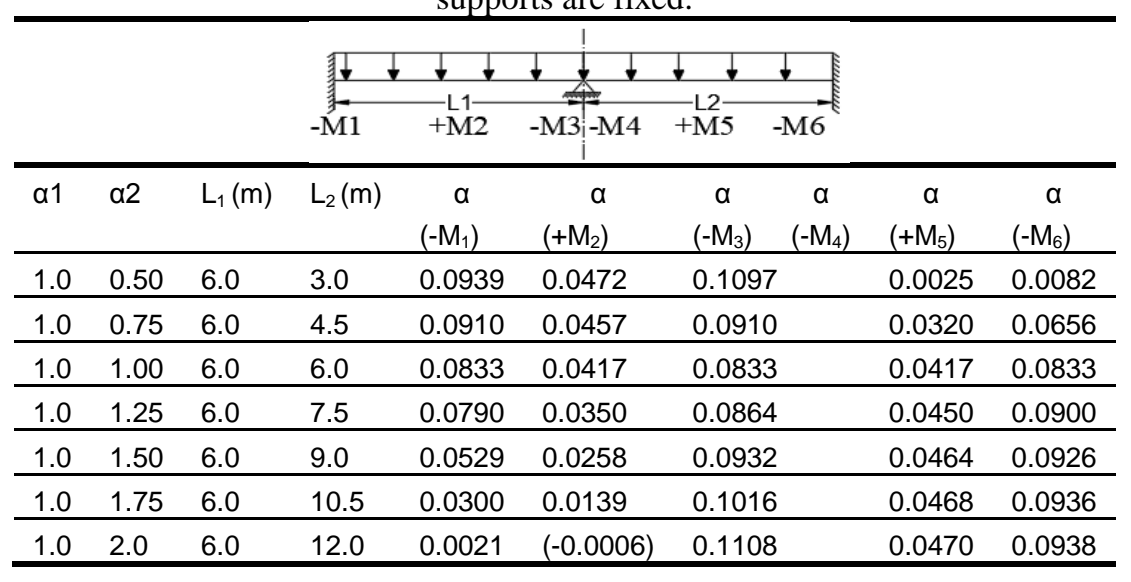

Table (14): Results of (moment coefficient) for continues three spans for different values of ( $\alpha 2 \& \alpha 3$ ), the external supports are simply supported.

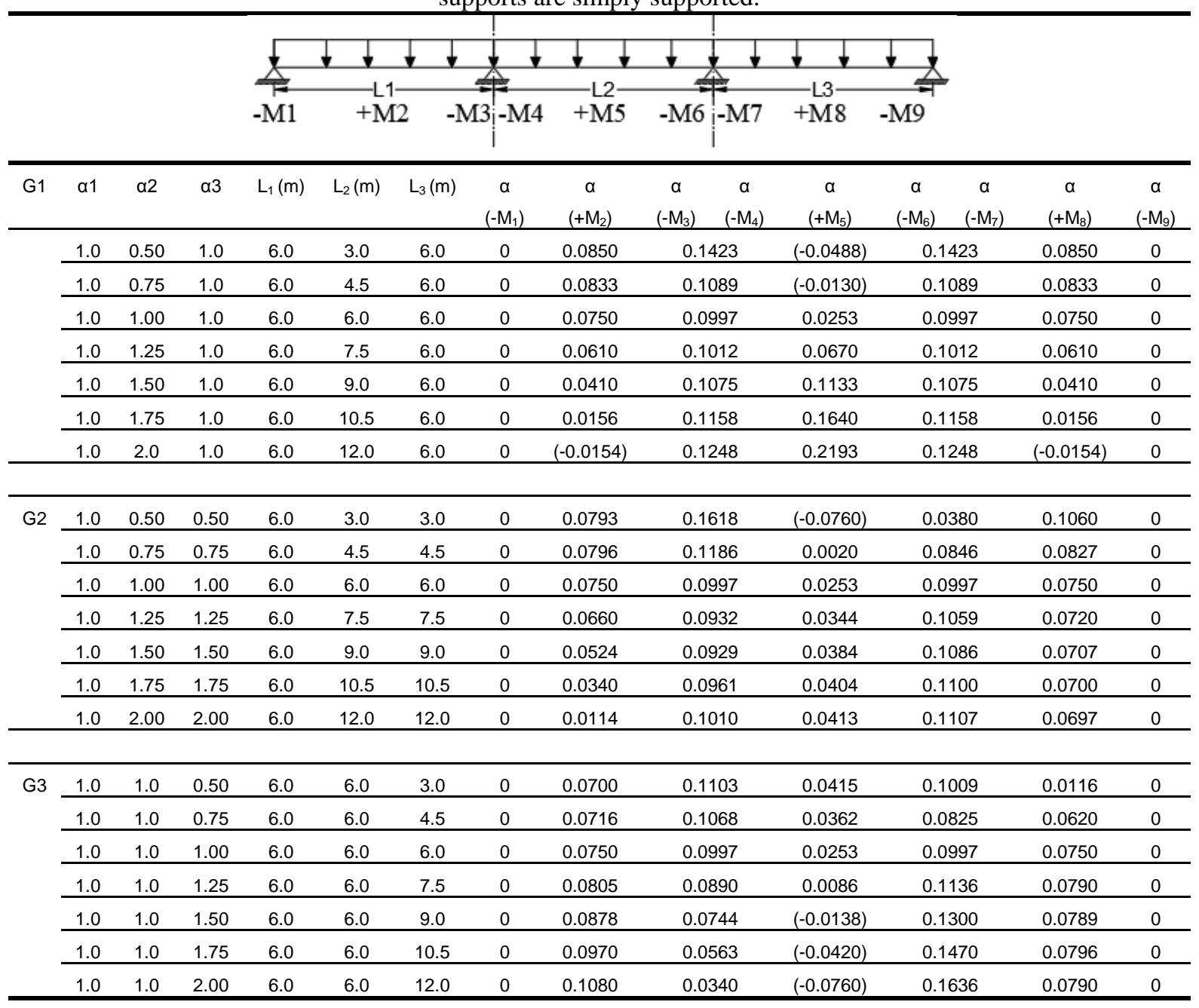


Table (15): Results of (moment coefficient) for continues three spans for different values of ( $\alpha 2 \& \alpha 3)$, the external supports are fixed.

\begin{tabular}{|c|c|c|c|c|c|c|c|c|c|c|c|c|c|}
\hline & & & & & & $\begin{array}{l}+ \\
-\mathrm{L} 1- \\
+\mathrm{M} 2\end{array}$ & -M3i-M & $\begin{array}{l}\downarrow \\
+\mathrm{L} 2- \\
+\mathrm{M} 5\end{array}$ & $\underbrace{\mid}_{-\mathrm{M} 6}$ & $+\frac{\downarrow}{+\mathrm{L} 3}$ & $-\mathrm{Mg}$ & & \\
\hline & $\alpha 1$ & $\alpha 2$ & $\alpha 3$ & $\mathrm{~L}_{1}(\mathrm{~m})$ & $\mathrm{L}_{2}(\mathrm{~m})$ & $\mathrm{L}_{3}(\mathrm{~m})$ & $\begin{array}{r}\alpha \\
\left(-M_{1}\right) \\
\end{array}$ & $\begin{array}{r}\alpha \\
\left(+M_{2}\right) \\
\end{array}$ & $\begin{array}{cc}\alpha & \alpha \\
\left(-M_{3}\right) & \left(-M_{4}\right) \\
\end{array}$ & $\begin{array}{r}\alpha \\
\left(+M_{5}\right) \\
\end{array}$ & $\begin{array}{cc}\alpha & \alpha \\
\left(-M_{6}\right) & \left(-M_{7}\right) \\
\end{array}$ & $\begin{array}{r}\alpha \\
\left(+M_{8}\right) \\
\end{array}$ & $\begin{array}{r}\alpha \\
\left(-M_{9}\right) \\
\end{array}$ \\
\hline \multirow[t]{7}{*}{ G1 } & 1 & 0.5 & 1 & 6.0 & 3.0 & 6.0 & 0.0985 & 0.0496 & 0.0930 & $(-0.0846)$ & 0.0930 & 0.0496 & 0.0985 \\
\hline & 1 & 0.75 & 1 & 6.0 & 4.5 & 6.0 & 0.0940 & 0.0472 & 0.0805 & 0.0154 & 0.0805 & 0.0472 & 0.0940 \\
\hline & 1 & 1.00 & 1 & 6.0 & 6.0 & 6.0 & 0.0835 & 0.0417 & 0.0833 & 0.0417 & 0.0833 & 0.0417 & 0.0835 \\
\hline & 1 & 1.25 & 1 & 6.0 & 7.5 & 6.0 & 0.0670 & 0.0330 & 0.0922 & 0.0504 & 0.0922 & 0.0330 & 0.0670 \\
\hline & 1 & 1.50 & 1 & 6.0 & 9.0 & 6.0 & 0.0453 & 0.0218 & 0.1031 & 0.0534 & 0.1031 & 0.0218 & 0.0453 \\
\hline & 1 & 1.75 & 1 & 6.0 & 10.5 & 6.0 & 0.0180 & 0.0077 & 0.1145 & 0.0543 & 0.1145 & 0.0077 & 0.0180 \\
\hline & 1 & 2.00 & 1 & 6.0 & 12.0 & 6.0 & $(-0.0142)$ & $(-0.0093)$ & 0.1256 & 0.0544 & 0.1256 & $(-0.0093)$ & $(-0.0142)$ \\
\hline \multirow[t]{7}{*}{ G2 } & 1 & 0.5 & 0.50 & 6.0 & 3.0 & 3.0 & 0.0947 & 0.0476 & 0.1069 & -0.0167 & 0.0430 & 0.0526 & 0.1019 \\
\hline & 1 & 0.75 & 0.75 & 6.0 & 4.5 & 4.5 & 0.0916 & 0.0460 & 0.0868 & 0.0290 & 0.0739 & 0.0441 & 0.0879 \\
\hline & 1 & 1.00 & 1.00 & 6.0 & 6.0 & 6.0 & 0.0833 & 0.0417 & 0.0833 & 0.0417 & 0.0833 & 0.0417 & 0.0833 \\
\hline & 1 & 1.25 & 1.25 & 6.0 & 7.5 & 7.5 & 0.0700 & 0.0347 & 0.0875 & 0.0460 & 0.0868 & 0.0408 & 0.0816 \\
\hline & 1 & 1.50 & 1.50 & 6.0 & 9.0 & 9.0 & 0.0513 & 0.025 & 0.0952 & 0.0478 & 0.0882 & 0.0404 & 0.0809 \\
\hline & 1 & 1.75 & 1.75 & 6.0 & 10.5 & 10.5 & 0.0275 & 0.0126 & 0.1044 & 0.048 & 0.0887 & 0.0403 & 0.0807 \\
\hline & 1 & 2.00 & 2.0 & 6.0 & 12.0 & 12.0 & $(-0.0014)$ & $(-0.0475)$ & 0.1140 & 0.0486 & 0.0888 & 0.0403 & 0.0806 \\
\hline \multirow[t]{7}{*}{ G3 } & 1 & 1.0 & 0.50 & 6.0 & 6.0 & 3.0 & 0.0806 & 0.0403 & 0.0889 & 0.0488 & 0.1129 & $(-0.0044)$ & 0.0049 \\
\hline & 1 & 1.0 & 0.75 & 6.0 & 6.0 & 4.5 & 0.0814 & 0.0406 & 0.0874 & 0.047 & 0.0897 & 0.0316 & 0.0646 \\
\hline & 1 & 1.0 & 1.00 & 6.0 & 6.0 & 6.0 & 0.0833 & 0.0417 & 0.0833 & 0.0417 & 0.0833 & 0.0417 & 0.0833 \\
\hline & 1 & 1.0 & 1.25 & 6.0 & 6.0 & 7.5 & 0.0867 & 0.0434 & 0.0765 & 0.0328 & 0.0852 & 0.0453 & 0.0904 \\
\hline & 1 & 1.0 & 1.50 & 6 & 6 & 9 & 0.0914 & 0.0458 & 0.0669 & 0.0204 & 0.0911 & 0.0467 & 0.0933 \\
\hline & 1 & 1.0 & 1.75 & 6 & 6 & 10.5 & 0.0975 & 0.049 & 0.0545 & 0.0043 & 0.0989 & 0.0473 & 0.0944 \\
\hline & 1 & 1.0 & 2.00 & 6 & 6 & 12 & 0.105 & 0.0529 & 0.0392 & $(-0.0156)$ & 0.1075 & 0.0474 & 0.0947 \\
\hline
\end{tabular}


Table (16): Results of (moment coefficient) for continues four spans for different group combination $(\alpha 2, \alpha 3 \& \alpha 4)$ values, the external supports are simply supported. $M=\alpha W L^{2}, \mathrm{~L}=$ Span for $(+\mathrm{M}), \mathrm{L}=$ Average span for $(-\mathrm{M})$

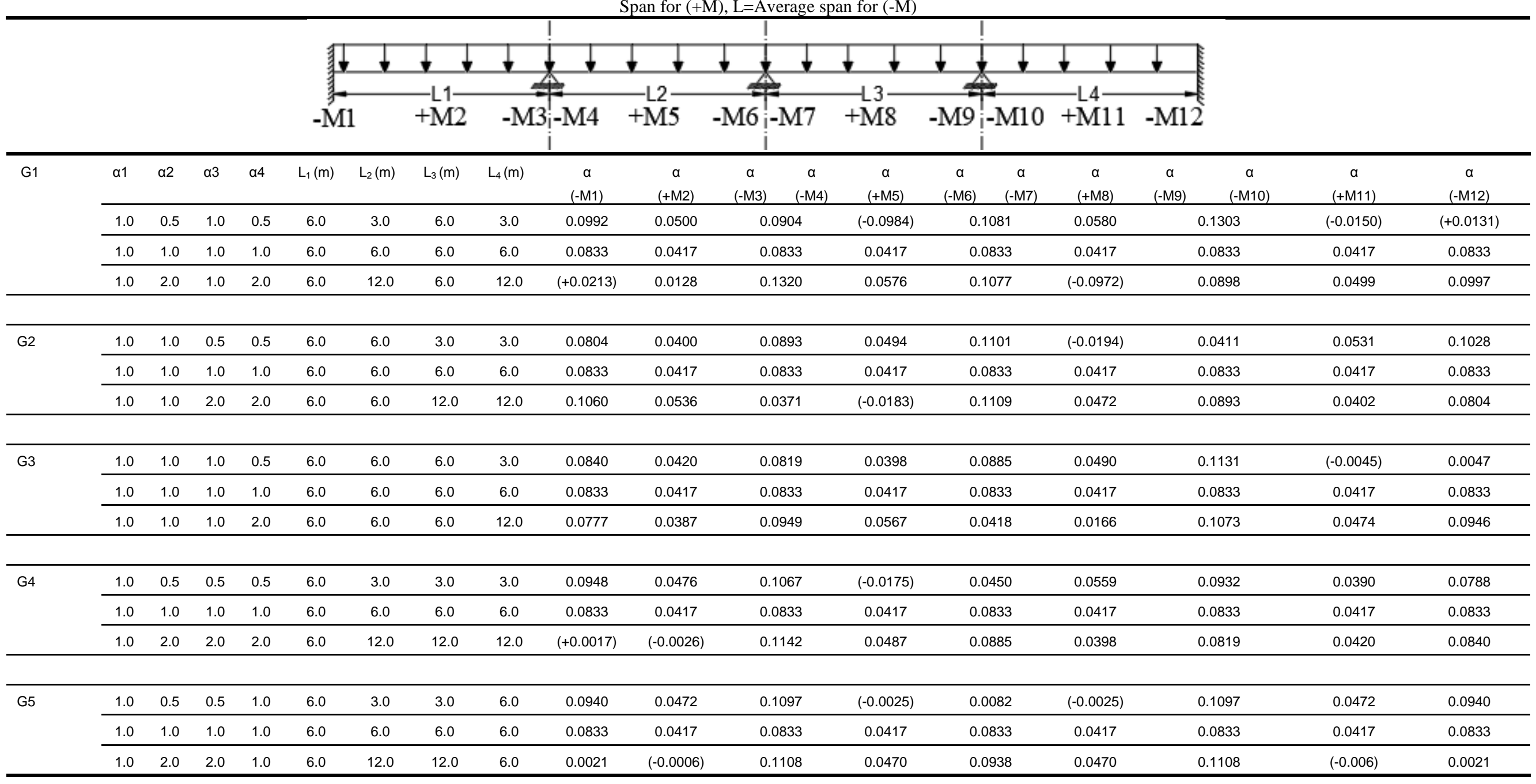


Table (17): Results of (moment coefficient) for continues four spans for different group combination $(\alpha 2, \alpha 3 \& \alpha 4)$ values, the external supports are fixed. $\mathrm{M}=\alpha \mathrm{WL}^{2}, \mathrm{~L}=\mathrm{Span}$ for $(+\mathrm{M}), \mathrm{L}=$ Average span for $(-\mathrm{M})$

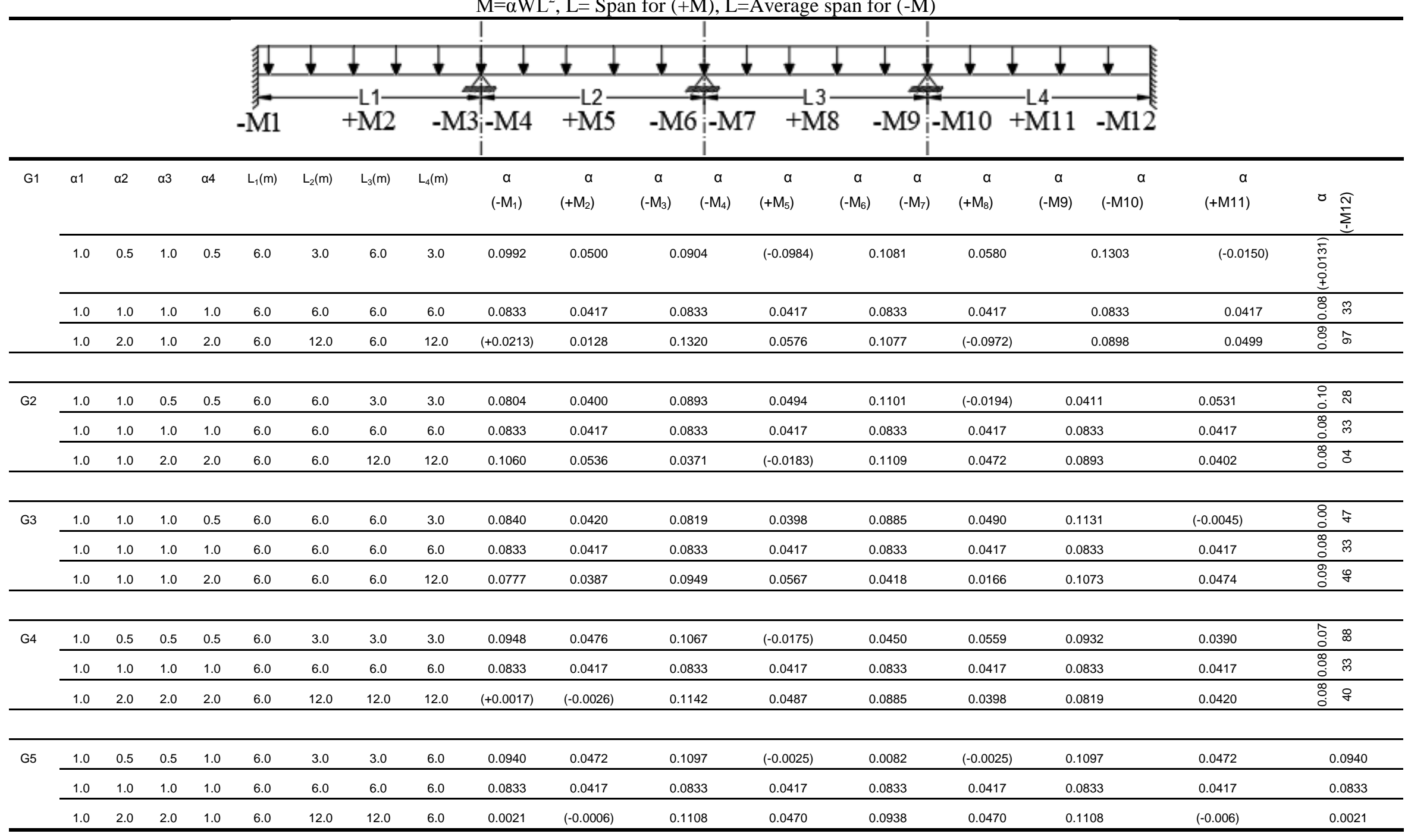


Table (18): Results of (moment coefficient) for continues four spans for different group combination $(\alpha 2, \alpha 3, \alpha 4 \& \alpha 5)$ values, the external supports are simply supported. $\mathrm{M}=\alpha \mathrm{WL}^{2}, \mathrm{~L}=$ Span for $(+\mathrm{M}), \mathrm{L}=$ Average span for $(-\mathrm{M})$

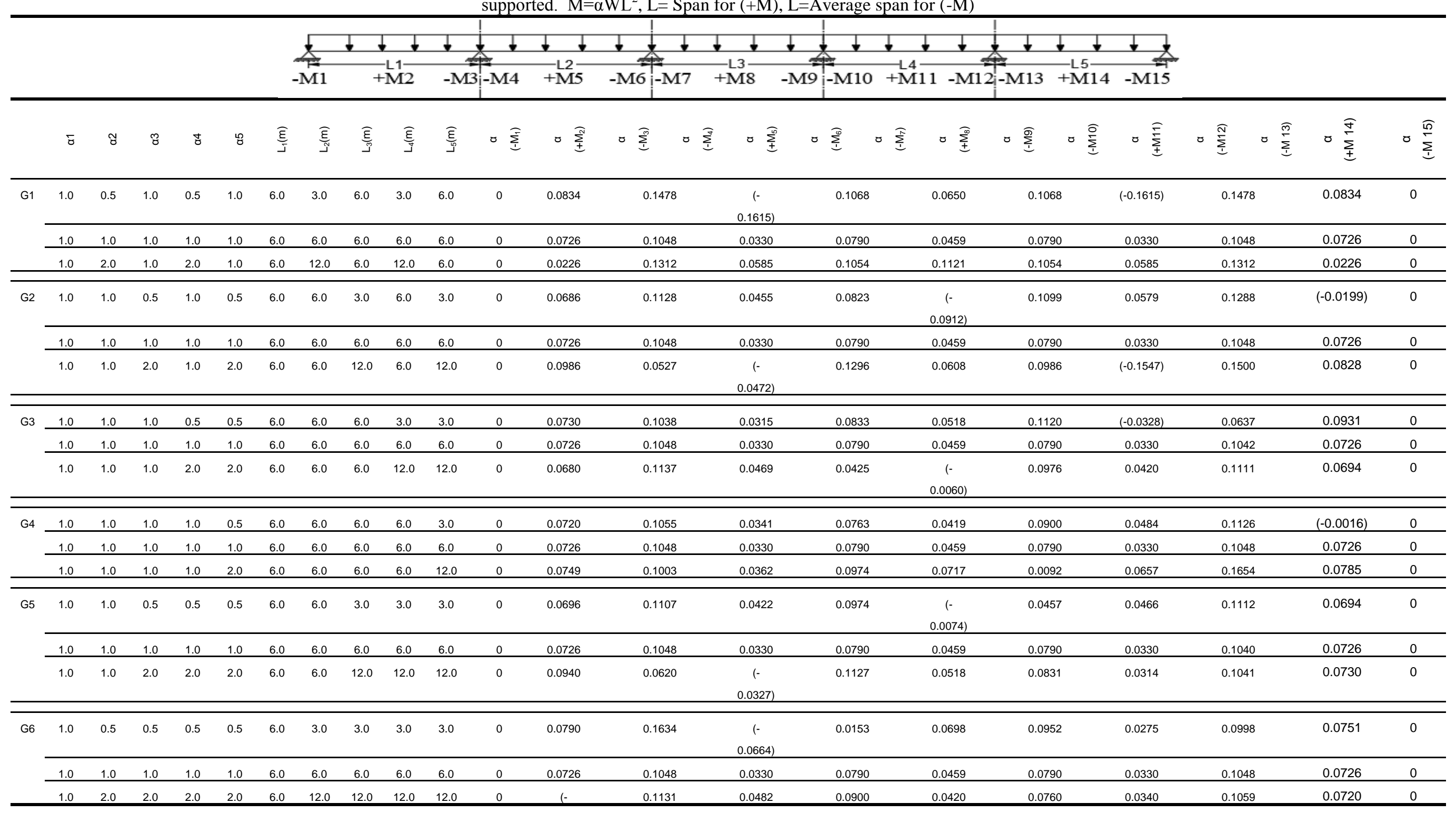




\begin{tabular}{|c|c|c|c|c|c|c|c|c|c|c|c|c|c|c|c|c|c|c|c|c|c|}
\hline & & & & & & & & & & & & $0.0022)$ & & & & & & & & & \\
\hline \multirow[t]{3}{*}{ G7 } & 1.0 & 1.0 & 0.5 & 1.0 & 1.0 & 6.0 & 6.0 & 3.0 & 6.0 & 6.0 & 0 & 0.0689 & 0.1123 & 0.0446 & 0.0796 & $\begin{array}{c}(- \\
0.0691)\end{array}$ & 0.0796 & 0.0446 & 0.1123 & 0.0689 & 0 \\
\hline & 1.0 & 1.0 & 1.0 & 1.0 & 1.0 & 6.0 & 6.0 & 6.0 & 6.0 & 6.0 & 0 & 0.0726 & 0.1048 & 0.0330 & 0.0790 & 0.0459 & 0.0790 & 0.0330 & 0.1048 & 0.0726 & 0 \\
\hline & 1.0 & 1.0 & 2.0 & 1.0 & 1.0 & 6.0 & 6.0 & 12.0 & 6.0 & 6.0 & 0 & 0.0965 & 0.0570 & $\begin{array}{c}(- \\
0.0404)\end{array}$ & 0.1216 & 0.0566 & 0.1216 & $(-0.0404)$ & 0.0570 & 0.0965 & 0 \\
\hline
\end{tabular}

Table (19): Results of (moment coefficient) for continues four spans for different group combination $(\alpha 2, \alpha 3, \alpha 4 \& \alpha 5)$ values, the external supports are fixed.

$\mathrm{M}=\alpha \mathrm{WL}^{2}, \mathrm{~L}=\operatorname{Span}$ for $(+\mathrm{M}), \mathrm{L}=$ Average span for $(-\mathrm{M})$

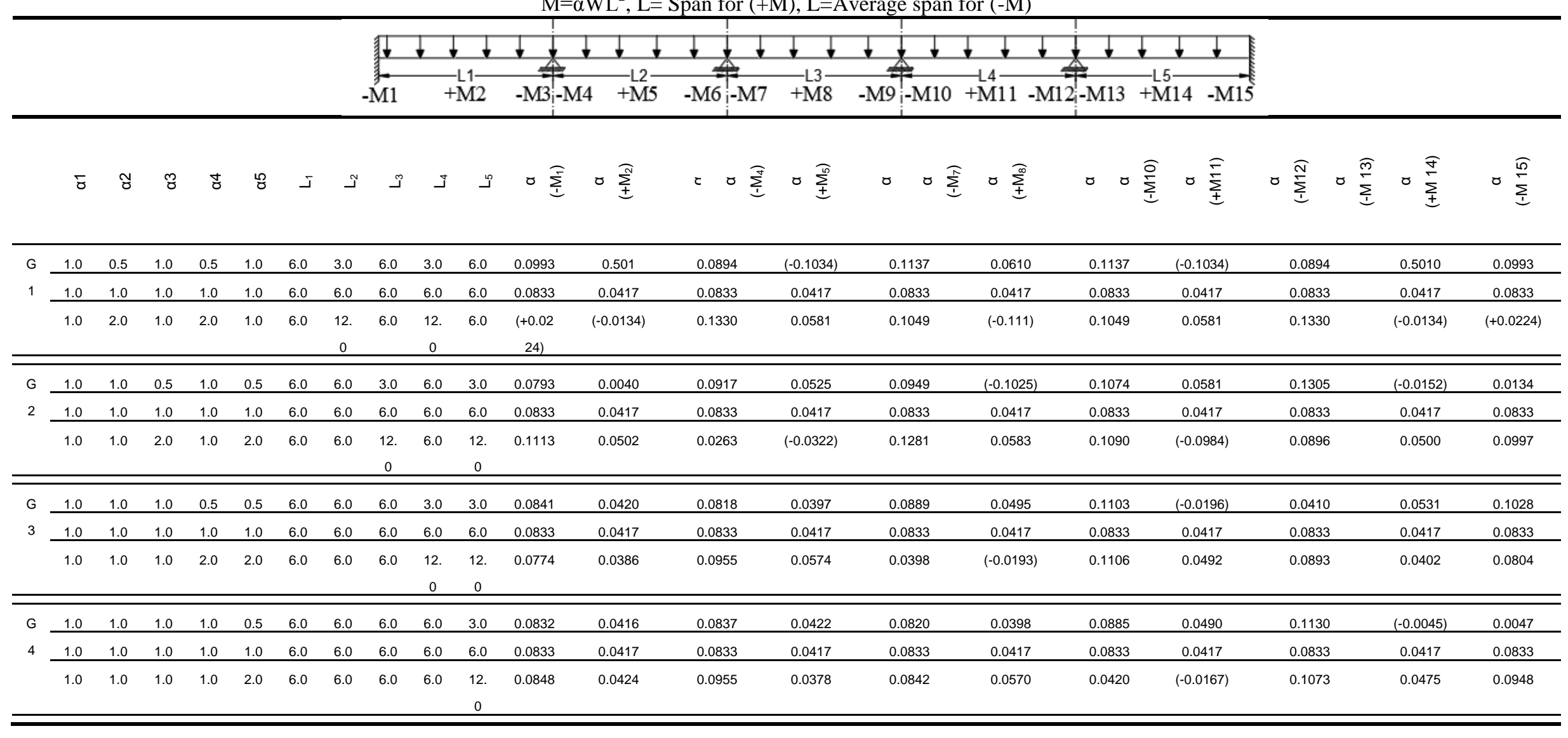


Journal of University of Duhok, Vol. 21, No.2 (Pure and Eng. Sciences), Pp 75-98, 2018

https://doi.org/10.26682/sjuod.2018.21.2.8

\begin{tabular}{|c|c|c|c|c|c|c|c|c|c|c|c|c|c|c|c|c|c|c|c|c|c|}
\hline G & 1.0 & 1.0 & 0.5 & 0.5 & 0.5 & 6.0 & 6.0 & 3.0 & 3.0 & 3.0 & 0.0804 & 0.0401 & 0.0893 & 0.0494 & 0.1099 & $(-0.0203)$ & 0.0433 & 0.0566 & 0.0936 & 0.0389 & 0.0786 \\
\hline \multirow[t]{3}{*}{5} & 1.0 & 1.0 & 1.0 & 1.0 & 1.0 & 6.0 & 6.0 & 6.0 & 6.0 & 6.0 & 0.0833 & 0.0417 & 0.0833 & 0.0417 & 0.0833 & 0.0417 & 0.0833 & 0.0417 & 0.0833 & 0.0417 & 0.0833 \\
\hline & 1.0 & 1.0 & 2.0 & 2.0 & 2.0 & 6.0 & 6.0 & 12. & 12. & 12. & 0.106 & 0.0535 & 0.0370 & $(-0.0185)$ & 0.1110 & 0.0493 & 0.0889 & 0.0397 & 0.0818 & 0.0420 & 0.0841 \\
\hline & & & & & & & & 0 & 0 & 0 & & & & & & & & & & & \\
\hline G & 1.0 & 0.5 & 0.5 & 0.5 & 0.5 & 6.0 & 3.0 & 3.0 & 3.0 & 3.0 & 0.0948 & 0.0476 & 0.1067 & $(-0.0176)$ & 0.0452 & 0.0561 & 0.0927 & 0.0382 & 0.0809 & 0.0423 & 0.0844 \\
\hline \multirow[t]{3}{*}{6} & 1.0 & 1.0 & 1.0 & 1.0 & 1.0 & 6.0 & 6.0 & 6.0 & 6.0 & 6.0 & 0.0833 & 0.0417 & 0.0833 & 0.0417 & 0.0833 & 0.0417 & 0.0833 & 0.0417 & 0.0833 & 0.0417 & 0.0833 \\
\hline & 1.0 & 2.0 & 2.0 & 2.0 & 2.0 & 6.0 & 12. & 12. & 12. & 12. & $(+0.00$ & $(-0.0026)$ & 0.1142 & 0.0467 & 0.0884 & 0.0398 & 0.0820 & 0.0421 & 0.0837 & 0.0416 & 0.0832 \\
\hline & & & & & & & 0 & 0 & 0 & 0 & 17) & & & & & & & & & & \\
\hline G & 1.0 & 1.0 & 0.5 & 1.0 & 1.0 & 6.0 & 6.0 & 3.0 & 6.0 & 6.0 & 0.0794 & 0.0396 & 0.0914 & 0.0521 & 0.0967 & $(-0.0926)$ & 0.0967 & 0.0521 & 0.0914 & 0.0396 & 0.0794 \\
\hline \multirow[t]{2}{*}{7} & 1.0 & 1.0 & 1.0 & 1.0 & 1.0 & 6.0 & 6.0 & 6.0 & 6.0 & 6.0 & 0.0833 & 0.0417 & 0.0833 & 0.0417 & 0.0833 & 0.0417 & 0.0833 & 0.0417 & 0.0833 & 0.0417 & 0.0833 \\
\hline & 1.0 & 1.0 & 2.0 & 1.0 & 1.0 & 6.0 & 6.0 & 12. & 6.0 & 6.0 & 0.1098 & 0.0554 & 0.0294 & $(-0.0283)$ & 0.1232 & 0.0557 & 0.1232 & $(-0.0283)$ & 0.0294 & 0.0554 & 0.1098 \\
\hline
\end{tabular}




\section{CONCLUSIONS}

The moment coefficient of different continuous multi spans are determined and compared with ACI-coefficient method of elastic analysis. Two, three, four and five multi spans continuous beam are analyzed for two cases, the external supports are simply supported and fixed. Different groups of combinations are considered taking span ratios between $(0.5$ and 2.0$)$.

1- In the analysis of three, four and five spans continuous beams, negative moments are appeared at midspan instead of positive moment which is expected in some group combinations of span ratios. Also, positive moment is appeared in supports instead of negative moment which is expected in ACI coefficient method.

2- For three spans continuous spans, negative moments are appeared at the midspan of middle beam when the difference between two adjacent spans greater than $(16.5 \%)$. This behavior is not appeared in ACI-coefficient method. For this reason, finite element method and moment distribution method are adopted, and the designer engineer should take this point into account, when the external outer supports are fixed, the negative moment at midspan of the middle beam is appeared when the difference between two adjacent spans greater than (32\%).

3- For continuous beams with external support are simply supported, the results of the ACI-method are adequate and conservative at all location except at internal support, bending moment of $\left(\mathrm{WL}^{2} / 10\right)$ is suggested at both sides of the support. 4- When the external supports are fixed, the bending moment $\left(\mathrm{WL}^{2} / 12\right)$ is suggested at both sides of the support.

5- For continuous portal frame, the end moments at the column decreased with increasing the column height, which is benefit to reduce the load eccentricity, i.e. increasing the load capacity (internal strength) of the column.

6- For single span portal frame, the end and midspan moments of the beam vary between the results of the full fixed ends condition and simply supported end condition depending on the ratio of the beam to column stiffness ratio.

7- Negative moment appears at some midspan and positive moment appears at supports in some span arrangement combinations, which is opposite to that obtained by the ACI- simplified method of analysis for nonprestressed continuous beams and one-way slabs.

\section{REFERENCES}

- Darwin D., Dolon C. W. and Nilson A. H. (2016), "Design of Concrete Structures", McoGraw Hill Education (India) Private Limited, Chennai, 15th edition, 780pp.

- ACI Code (2014); "Building Code Requirements for Structural Concrete and Commentary", ACI 318-2014, American Concrete Institute, Forming Hills, MI 48331, USA; 520pp.

- John L. and Rajendran M. G. (2013), "Comparative Studies on Exact and Approximate Methods of Structural Analysis", International Journal of Engineering Research and Applications (IJERA), Vol. 3, Issue 2, March-April, pp. 764769.

- JingHai Wu, Engr. (1995), "Approximate analysis of building frames for vertical loads" - Journal of Structural Engineering, Vol. 121. No.4., April, pp. 784-787.

- R. A. Behr (1989), "Potential errors in approximate methods of structural analysis" , Journal of Structural Engineering, Vol. 115, No. 4, April, pp. 1002-1005.

- R. A. Behr, E. J. Grotton, and C. A. Dwinal (1990) "Revised method of approximate structural analysis", Journal of Structural Engineering, Vol. 116, No. 11, November, pp. 3242-3248.

- Marefat M. S. and Farzanian M. Sh. (2008), "Evaluation of Momenet Redistribution Demand in Contiuous Constructions under Gravity and Seismic Loads", The $14^{\text {th }}$ Conference on Earhquake Engineering, October 12-17, Beijing, China.

- Varia D.J. and Patel H. S.(2015), "Comparative Study of Classical Method and Relative Deformation Coefficient Approach for Contiuous Beam Analysis", International Journal of Civil Engineering and Technology (IJCIET), Vol. 6, Issue 11, November, pp. 164172.

- Varia D.J. and Patel H. S., "Parametruc Study of An Innovative Approximate Method of Continuous Beam", International Journal of Engineering Development and Research (IJEDR), IJEDR B02003,www. ijedr.org, editer@ijedr.org, pp. $12-16$.

- Varia D.J. and Patel H. S. (2015), "Analysis of Statically Indeterminate Beams Using an Innovative Approximate method", International Journal on recent and Innovation Trends in 
Computing and Communication, Vol. 3, Issue 2, Febreury, pp. 11-13.

- Kolekar D. M. and Pawat M. M. (2017), "Evaluation of Shear and Moment Coefficient for
Continuous Beam Considering Seiemic Forces", IJESC, Vol. 7, Issue No. 6, November.

\section{Appendix (A): Figures}

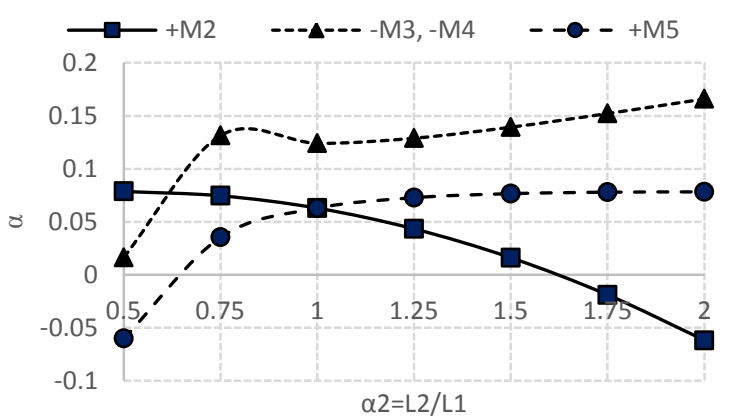

(A1): Moment coefficients of two span continuous beams with the span ratio ( $\alpha 2)$, the external supports are simply supported.

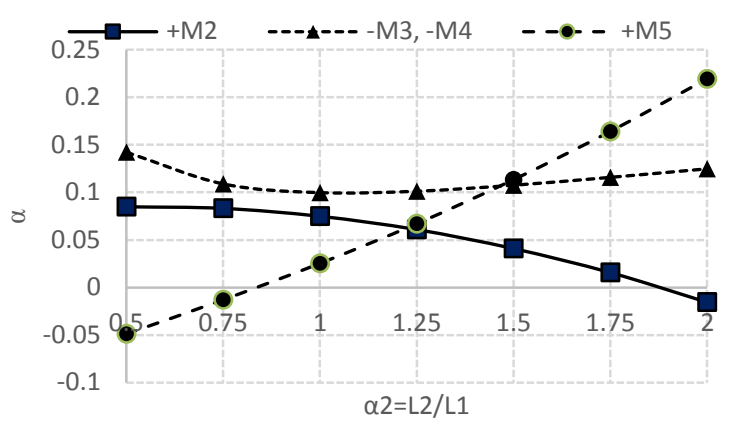

Fig. (A3): Moment coefficients of three spans continuous beams for group (G1), the external supports are simply supported.

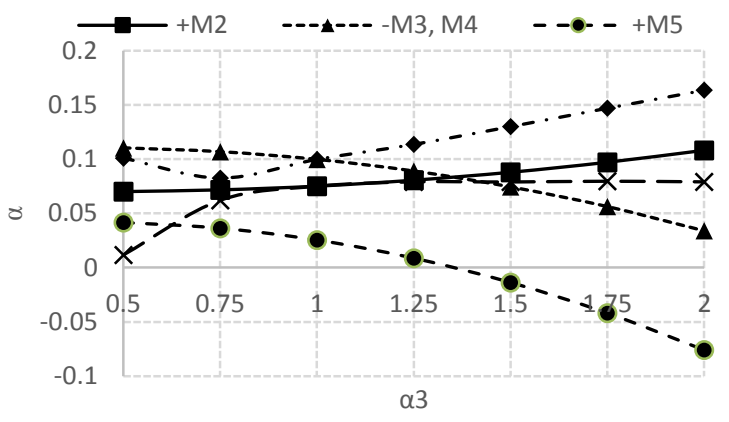

Fig. (A5): Moment coefficients of three spans continuous beams for group (G3), the external supports are simply supported.

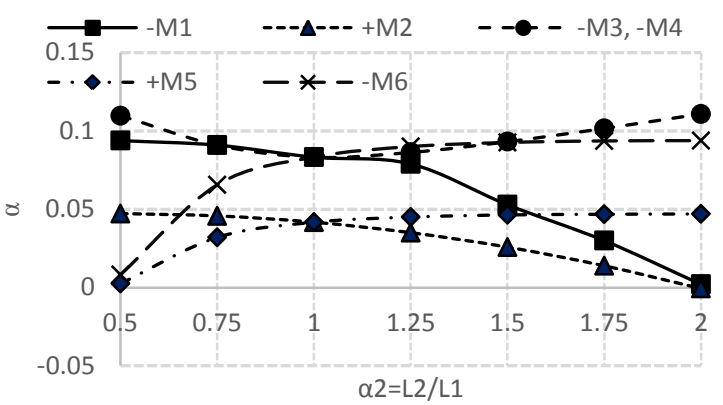

Fig. (A2): Moment coefficients of two span continuous beams with the span ratio $(\alpha 2)$, the external supports are fixed.

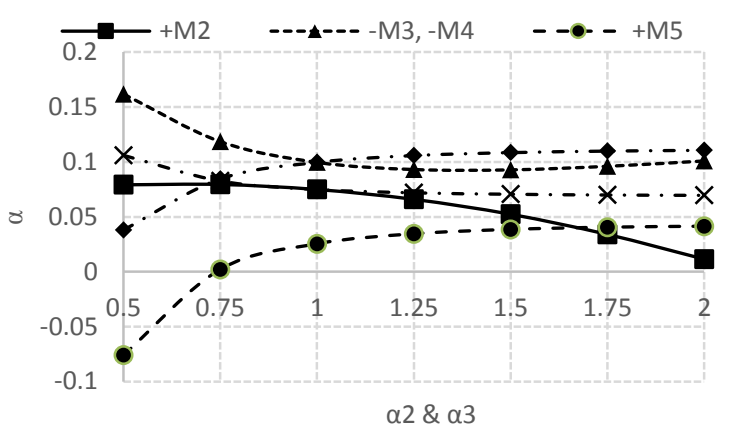

Fig. (A4): Moment coefficients of three spans continuous beams for group $(\mathrm{G} 2)$, the external supports are simply supported.

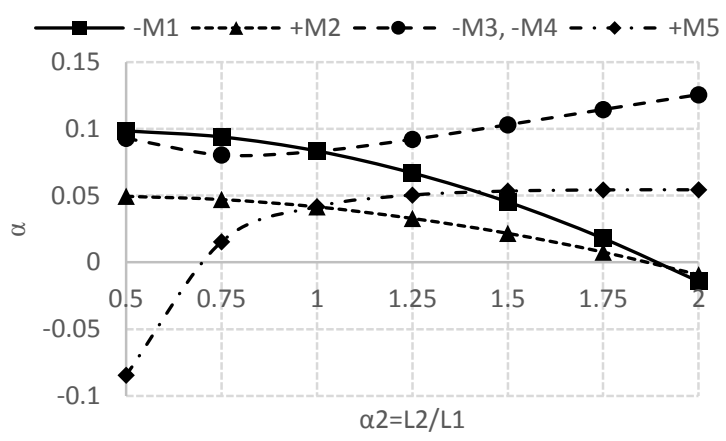

Fig. (A6): Moment coefficients of three spans continuous beams for group (G1), the external supports are fixed. 


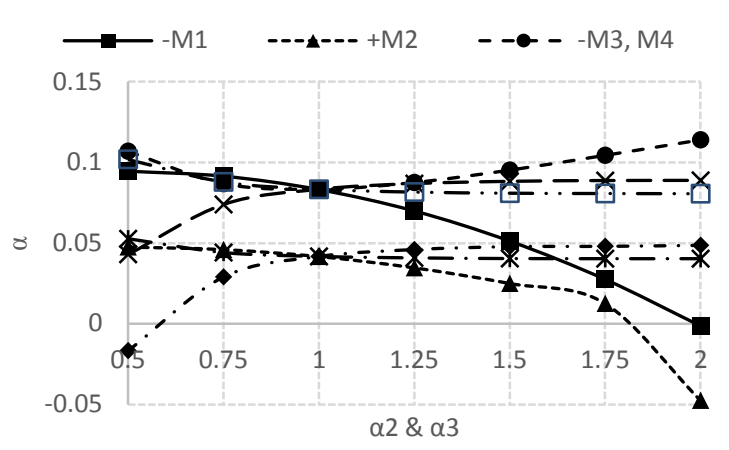

Fig. (A7): Moment coefficients of three spans continuous beams for group (G2), the external supports are fixed.

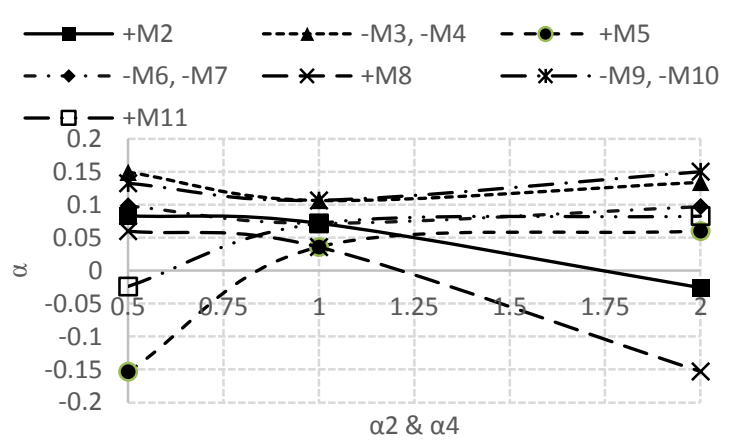

Fig. (A9): Moment coefficients of four spans continuous beams for group (G1), the external supports are simply

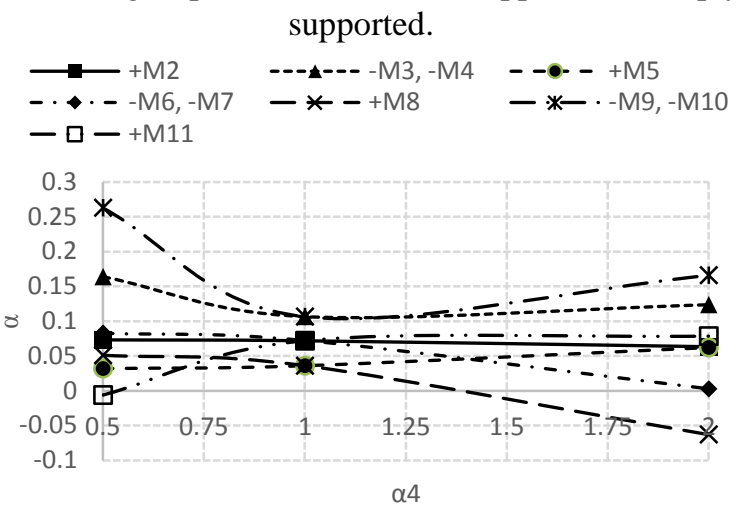

Fig. (A11): Moment coefficients of four spans continuous beams for group (G3), the external supports are simply supported.

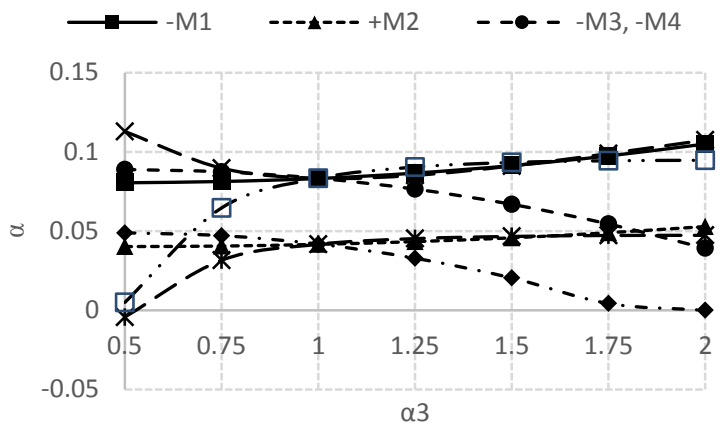

Fig. (A8): Moment coefficients of three spans continuous beams for group (G3), the external supports are fixed.

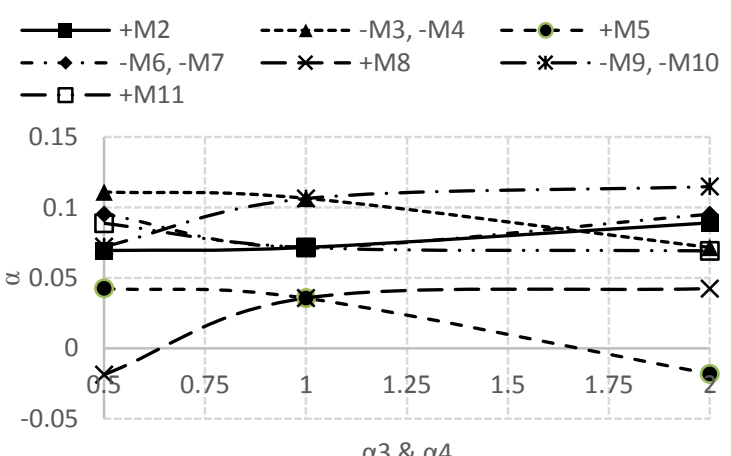

Fig. (A10): Moment coefficients of four spans continuous beams for group (G2), the external supports are simply supported.

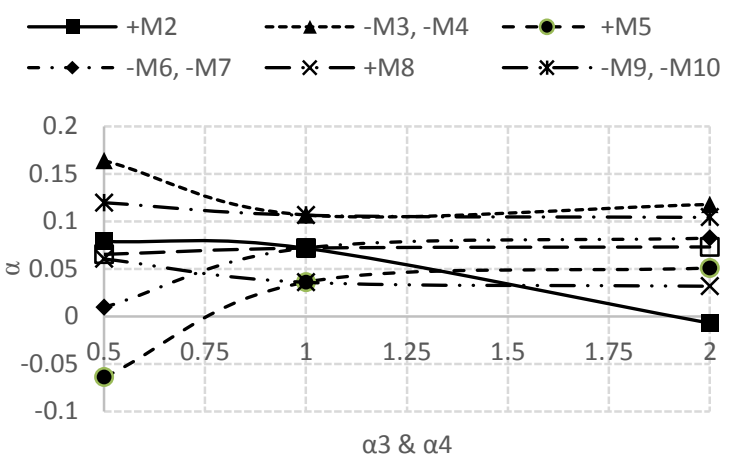

Fig. (A12): Moment coefficients of four spans continuous beams for group (G4), the external supports are simply supported. 


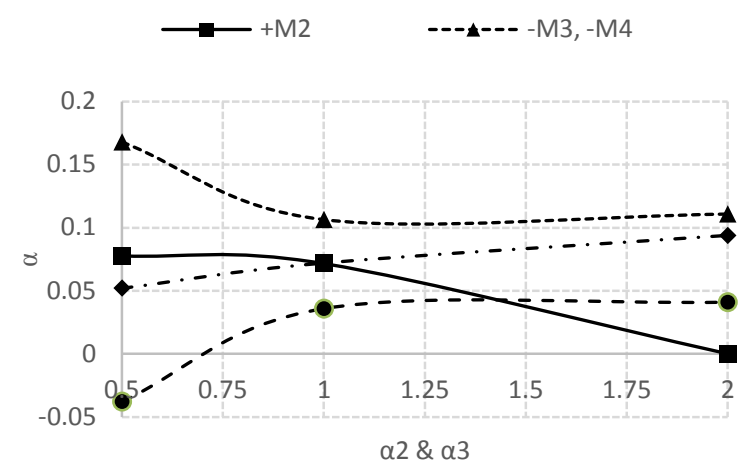

Fig. (A13): Moment coefficients of four spans continuous beams for group (G5), the external supports are simply supported.

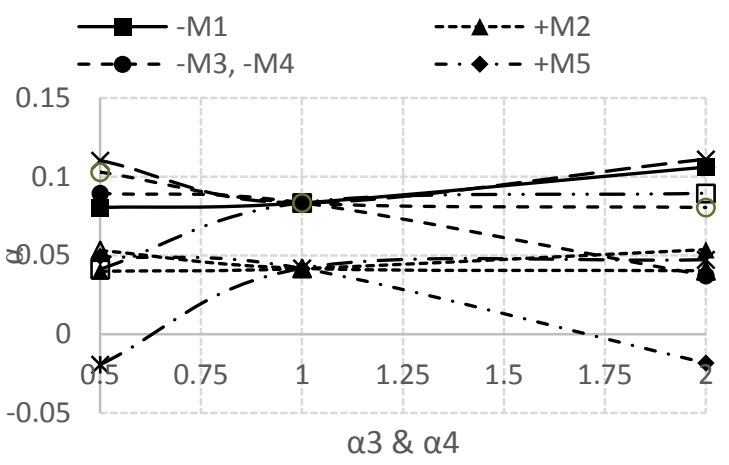

Fig. (A15): Moment coefficients of four spans continuous beams for group (G2), the external supports are fixed.

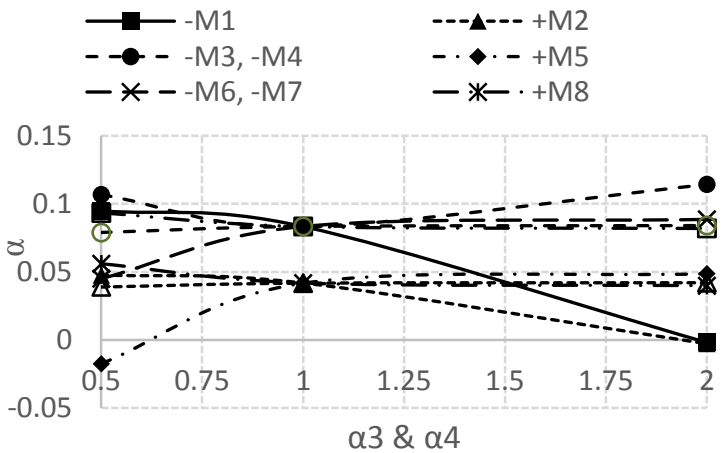

Fig. (A17): Moment coefficients of four spans continuous beams for group (G4), the external supports are fixed.

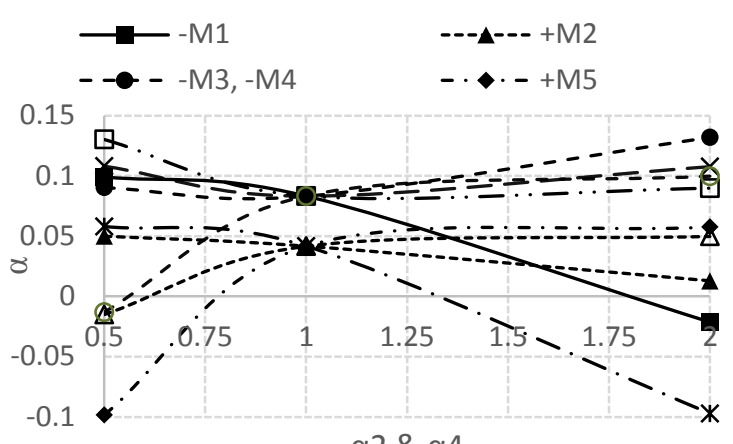

$\alpha 2 \& \alpha 4$

Fig. (A14): Moment coefficients of four spans continuous beams for group (G1), the external supports are fixed.

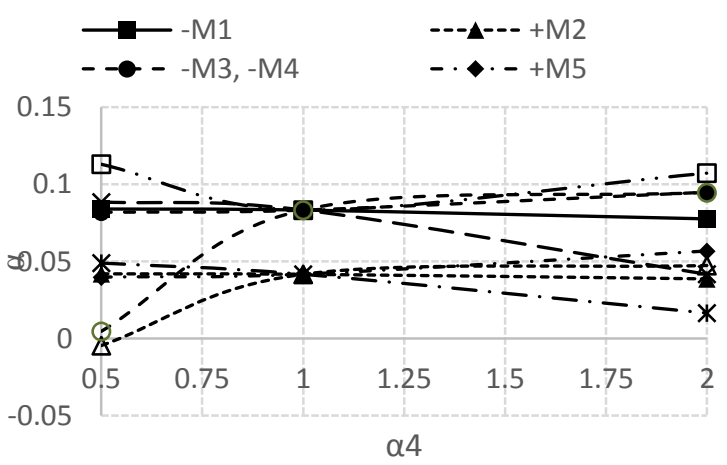

Fig. (A16): Moment coefficients of four spans continuous beams for group (G3), the external supports are fixed.

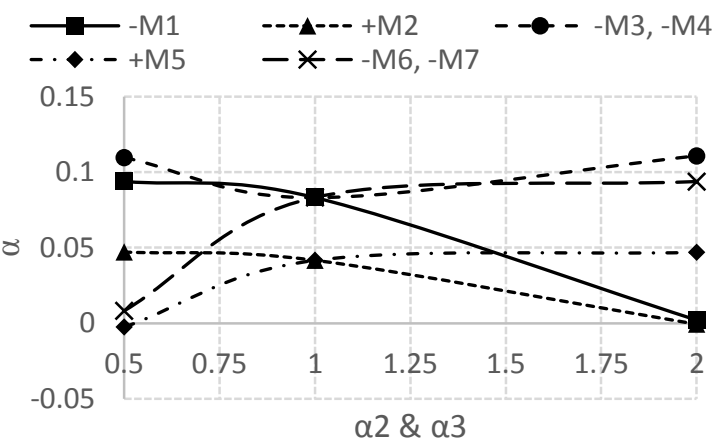

Fig. (A18): Moment coefficients of four spans continuous beams for group (G5), the external supports are fixed. 


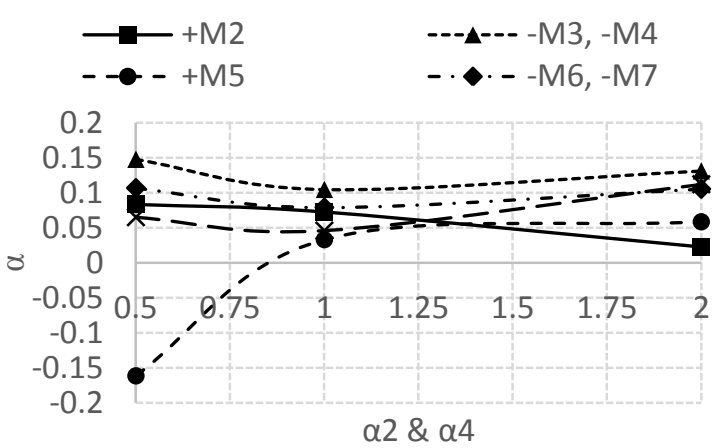

Fig. (A19): Moment coefficients of five spans continuous beams for group (G1), the external supports are simply supported.

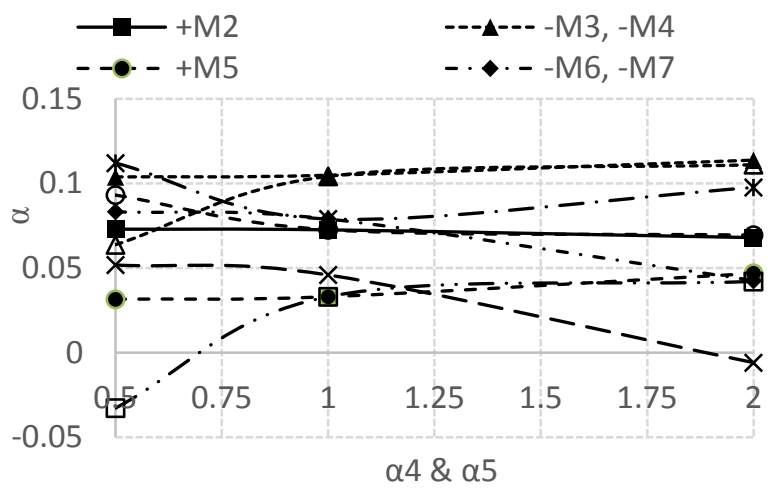

Fig. (A21): Moment coefficients of five spans continuous beams for group (G3), the external supports are simply supported.

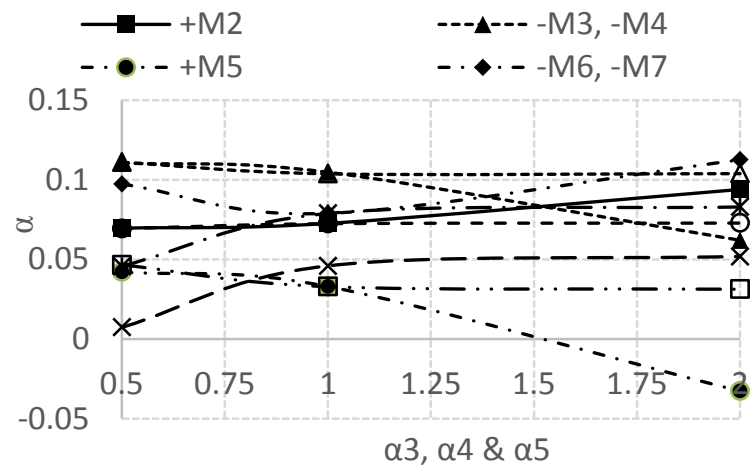

Fig. (A23): Moment coefficients of five spans continuous beams for group (G5), the external supports are simply supported.

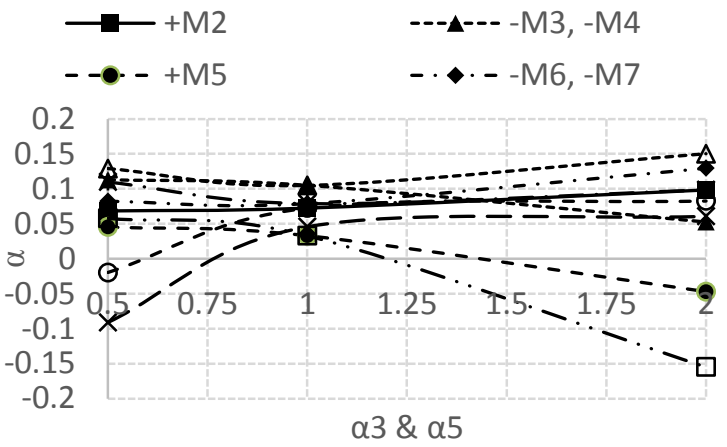

Fig. (A20): Moment coefficients of five spans continuous beams for group (G2), the external supports are simply supported.

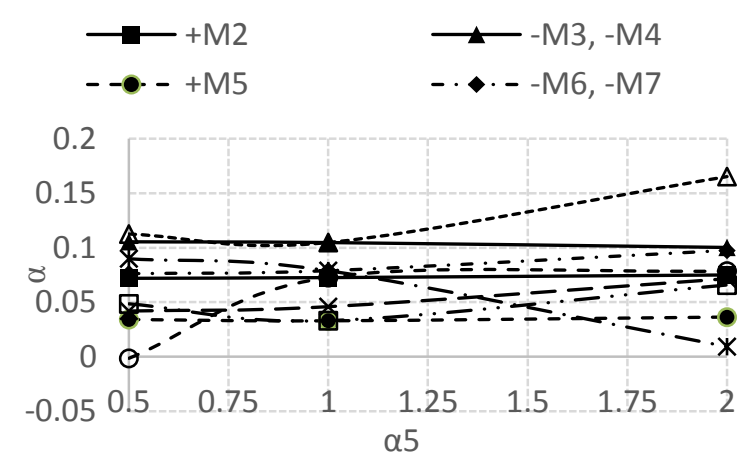

Fig. (A22): Moment coefficients of five spans continuous beams for group (G4), the external supports are simply supported.

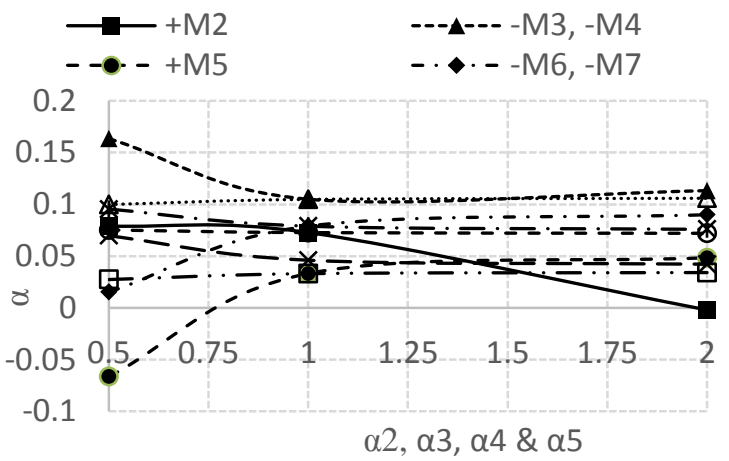

Fig. (A24): Moment coefficients of five spans continuous beams for group (G6), the external supports are simply supported. 


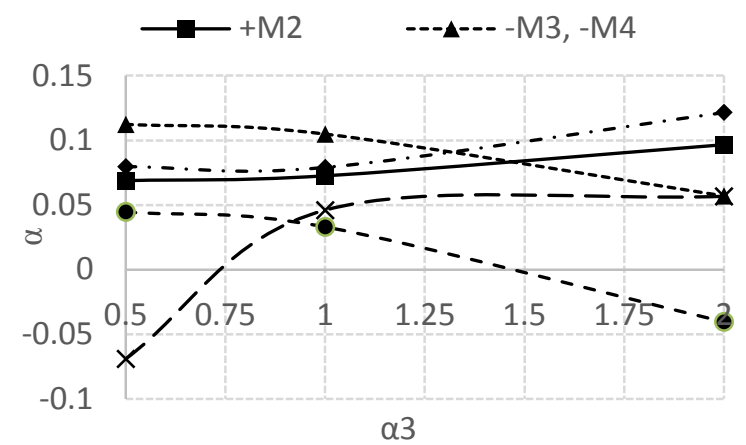

Fig. (A25): Moment coefficients of five spans continuous beams for group (G7), the external supports are simply supported.

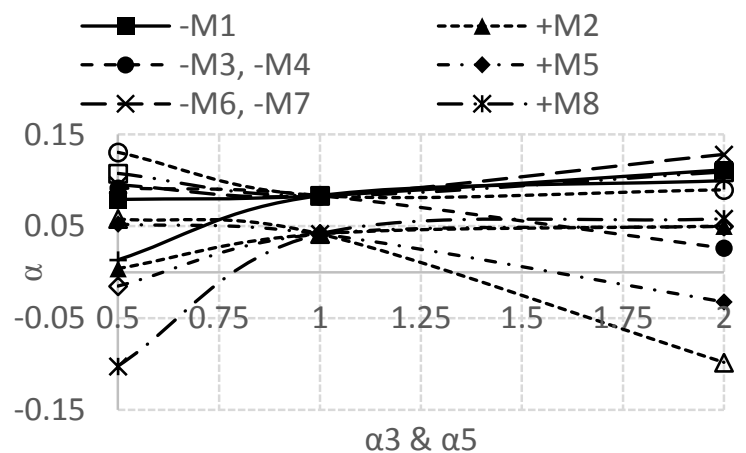

Fig. (A27): Moment coefficients of five spans continuous beams for group (G2), the external supports are fixed.

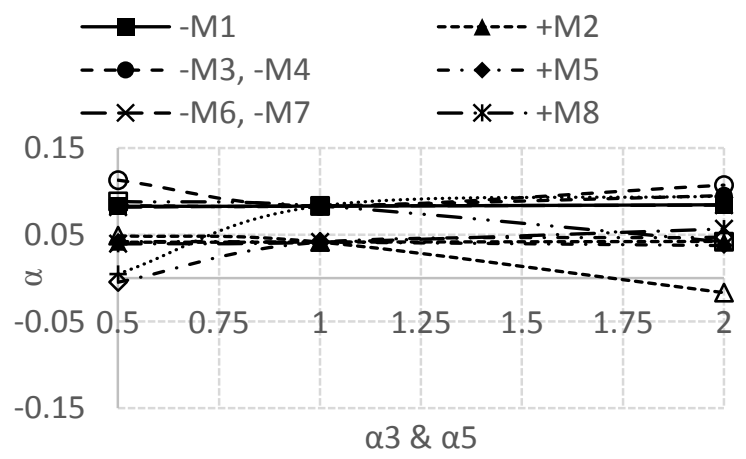

Fig. (A29): Moment coefficients of five spans continuous beams for group (G4), the external supports are fixed.

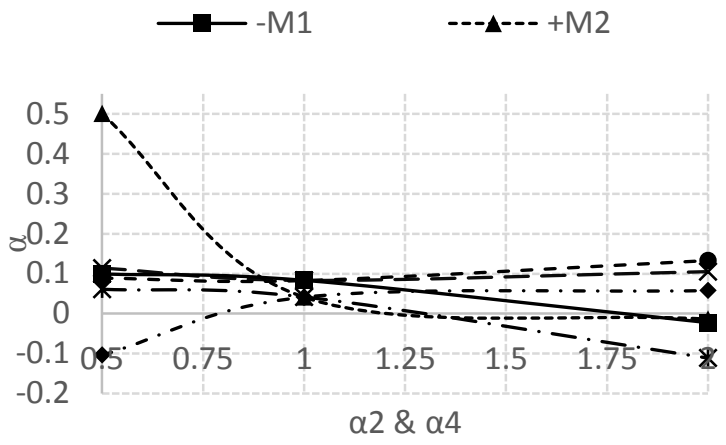

Fig. (A26): Moment coefficients of five spans continuous beams for group (G1), the external supports are fixed.

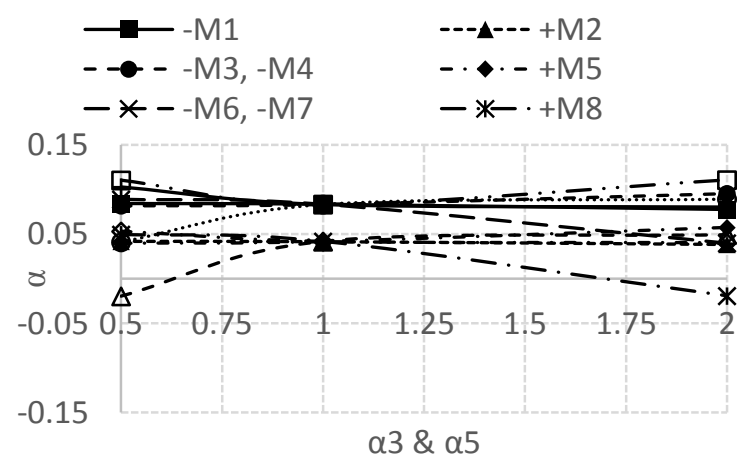

Fig. (A28): Moment coefficients of five spans continuous beams for group (G3), the external supports are fixed.

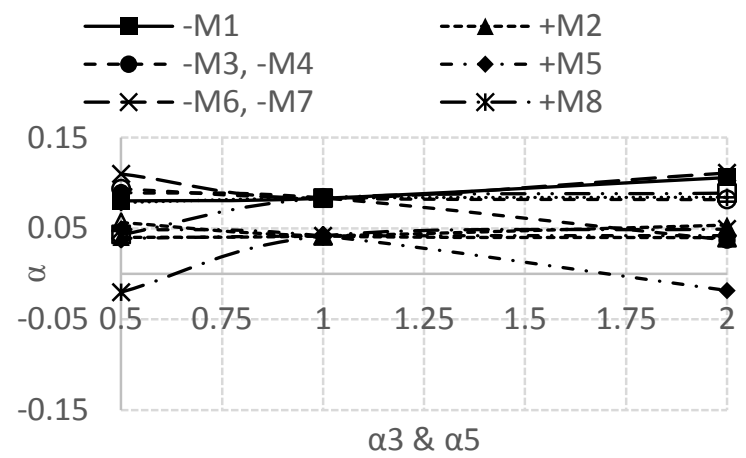

Fig. (A30): Moment coefficients of five spans continuous beams for group (G5), the external supports are fixed. 


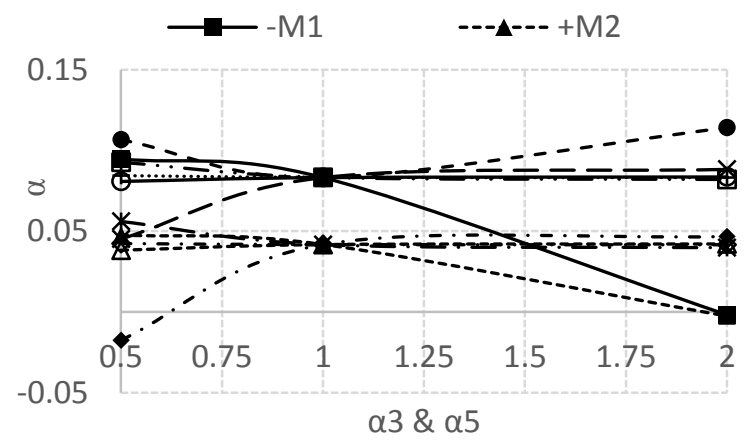

Fig. (A31): Moment coefficients of five spans continuous beams for group (G6), the external supports are fixed.

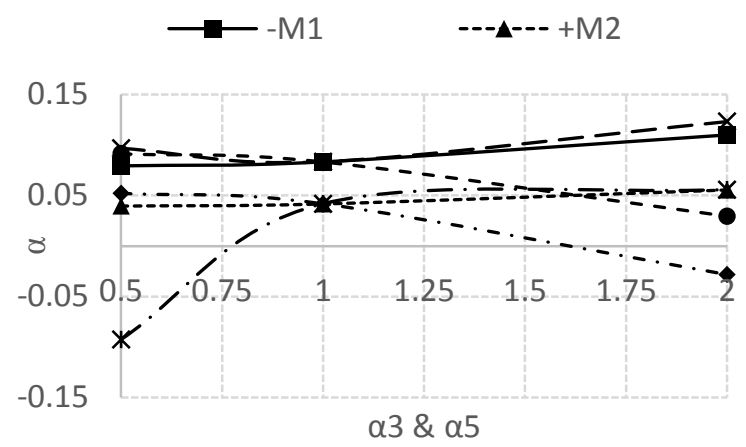

Fig. (A32): Moment coefficients of five spans continuous beams for group (G7), the external supports are fixed. 